\title{
Performance of the line-by-line radiative transfer model (LBLRTM) for temperature and species retrievals: IASI case studies from JAIVEx
}

\author{
M. W. Shephard ${ }^{1}$, S. A. Clough ${ }^{2}$, V. H. Payne ${ }^{1}$, W. L. Smith ${ }^{3,4}$, S. Kireev ${ }^{4}$, and K. E. Cady-Pereira ${ }^{1}$ \\ ${ }^{1}$ Atmospheric and Environmental Research, Inc., Lexington, Massachusetts, USA \\ ${ }^{2}$ Clough Radiation Associates, LLC., Lexington, Massachusetts, USA \\ ${ }^{3}$ University of Wisconsin, Madison, Wisconsin, USA \\ ${ }^{4}$ Hampton University, Hampton, Virginia, USA
}

Received: 25 February 2009 - Published in Atmos. Chem. Phys. Discuss.: 9 April 2009

Revised: 24 July 2009 - Accepted: 16 August 2009 - Published: 5 October 2009

\begin{abstract}
Presented here are comparisons between the Infrared Atmospheric Sounding instrument (IASI) and the "Line-By-Line Radiative Transfer Model" (LBLRTM). Spectral residuals from radiance closure studies during the IASI JAIVEx validation campaign provide insight into a number of spectroscopy issues relevant to remote sounding of temperature, water vapor and trace gases from IASI. In order to perform quality IASI trace gas retrievals, the temperature and water vapor fields must be retrieved as accurately as possible. In general, the residuals in the $\mathrm{CO}_{2} \nu_{2}$ region are of the order of the IASI instrument noise. However, outstanding issues with the $\mathrm{CO}_{2}$ spectral regions remain. There is a large residual $\sim-1.7 \mathrm{~K}$ in the $667 \mathrm{~cm}^{-1} \mathrm{Q}$ branch, and residuals in the $\mathrm{CO}_{2} v_{2}$ and $\mathrm{N}_{2} \mathrm{O} / \mathrm{CO}_{2} v_{3}$ spectral regions that sample the troposphere are inconsistent, with the $\mathrm{N}_{2} \mathrm{O} / \mathrm{CO}_{2} \quad v_{3}$ region being too negative (warmer) by $\sim 0.7 \mathrm{~K}$. Residuals on this lower wavenumber side of the $\mathrm{CO}_{2} \nu_{3}$ band will be improved by line parameter updates, while future efforts to reduce the residuals reaching $\sim-0.5 \mathrm{~K}$ on the higher wavenumber side of the $\mathrm{CO}_{2} \nu_{3}$ band will focus on addressing limitations in the modeling of the $\mathrm{CO}_{2}$ line shape (line coupling and duration of collision) effects. Brightness temperature residuals from the radiance closure studies in the $\nu_{2}$ water vapor band have standard deviations of $\sim 0.2-0.3 \mathrm{~K}$ with some large peak residuals reaching $\pm 0.5-1.0 \mathrm{~K}$. These are larger than the instrument noise indicating that systematic errors still remain. New $\mathrm{H}_{2} \mathrm{O}$ line intensities and positions
\end{abstract}

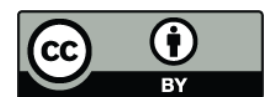

Correspondence to: M. W. Shephard (mshephar@aer.com) have a significant impact on the retrieved water vapor, particularly in the upper troposphere where the water vapor retrievals are $10 \%$ drier when using line intensities compared with HITRAN 2004. In addition to $\mathrm{O}_{3}, \mathrm{CH}_{4}$, and $\mathrm{CO}$, of the IASI instrument combined with an accurate forward model allows for the detection of minor species with weak atmospheric signatures in the nadir radiances, such as $\mathrm{HNO}_{3}$ and OCS.

\section{Introduction}

The accuracy to which it is possible to measure and to forecast atmospheric constituents such as temperature and trace gases from space is governed by both the absolute accuracy of current satellite instrumentation and by leading edge radiative transfer models. Limiting factors on accuracy include the noise on the measurement as well as systematic errors from both the instrument and the forward (radiative transfer) model. To attain the retrieval accuracies of which the present and next generation of passive remote sensors are capable, systematic errors, most especially those associated with errors in the spectral line calculation, must be reduced to an absolute minimum. High spectral resolution is critical to identify and separate the underlying causes of systematic errors. Presented here are comparisons between the Infrared Atmospheric Sounding Instrument (IASI), an infrared spectrometer on the MeteoSat MetOp satellite launched in 2006, and an advanced forward model, the "Line-By-Line Radiative Transfer Model" (LBLRTM). The high quality of both the measurements and the model provide the means to

Published by Copernicus Publications on behalf of the European Geosciences Union. 
validate both the IASI radiances and the spectroscopy used in the forward model. Systematic errors associated with either the inputs used in the forward model or with the instrument can result in various types of inconsistency that may limit the usefulness of the radiances for assimilation or remote sensing. Forward model errors can arise from imperfect knowledge of the spectroscopic parameters used or from errors in the instrument function used in the calculations. From an instrument perspective, discrepancies in the spectral or radiometric calibration between different spectral regions can also result in inconsistencies. The broad spectral range of the IASI instrument allows an assessment of consistencies of the modeling of different trace gases and between different spectral regions for a trace gas. IASI's spectral resolution and signal-to-noise ratio (SNR) provides the opportunity to examine the spectral signature of errors in detail, offering insight into any underlying issues with the spectroscopy used in the forward model.

Spectrally resolved infrared radiance measurements offer high vertical resolution sounding information on a range of atmospheric constituents. The concept of using high spectral resolution, quasi-continuous infrared radiance spectra for high vertical resolution sounding of the atmosphere was first demonstrated with the High spectral resolution Interferometer Sounder (HIS), flown on the NASA ER-2 aircraft in the 1980s. HIS and its successor, Scanning-HIS, have resulted in the development of calibration techniques that have allowed the excellent radiometric and spectral calibration achievable in today's instruments (e.g. Revercomb et al., 1988, 2003). The focus of this work will be the Infrared Atmospheric Sounding Interferometer (IASI), (e.g. Amato et al., 1995; Clerbaux et al., 2007; Phulpin et al., 2007, and http://smsc.cnes.fr/IASI/).

The motivation for the work presented here is to provide an assessment both of the quality of the spectral measurements and of the current capability in line-by-line radiative transfer modeling, where the main limitations on accuracy stem from uncertainties in the spectroscopic parameters used as input. We assess the potential accuracy based on the best knowledge we have available, with the goal in mind of improving the model from the approach of pushing for improvements based on a better understanding of the physics involved. An alternative approach, is simply to tune the forward model to ensure consistency with selected datasets. The tuning of models can certainly have merit in an operational framework, since it can help to smooth over various problems that could otherwise occur in operational analyses. However, tuning the model inevitably involves some assumptions and some ties to the "training dataset" used for the tuning. Also, tuning the model does not escape the fact that there are gaps in our understanding, which can become problematic when evaluating potential forward model improvements (e.g. evaluating water vapor line intensities presented in this study).

We perform radiance closure studies using high resolution spectral residuals across a wide spectral region to provide the means to assess the consistency 1) between different spectral bands for both measurement and model, 2) of the spectroscopy for different atmospheric trace gases in the model and 3) of the spectroscopy of a given trace gas in different bands.

The following section describes the current status of LBLRTM, while Sect. 3 provides an overview of the IASI instrument. Section 4 provides a description of the radiance closure approach and of the specific measurement cases chosen for the comparison. Section 5 presents the results and the discussion, while Sect. 6 provides conclusions.

\section{LBLRTM}

The Line-by-Line Radiative Transfer Model (LBLRTM) is an accurate and flexible radiative transfer model that can be used over the full spectral range from the microwave to the ultraviolet, providing the foundation for many radiative transfer applications. LBLRTM has a long and successful heritage at the leading edge of the field. LBLRTM is used in the training of IASI's operational model sigma-IASI (Amato et al., 2002) and has been utilized by the IASI Sounder Science Working Group (ISSWG) (Tjemkes et al., 2003). In addition to IASI, the model has been widely used for a number of years as the starting point for many retrieval algorithms (e.g. TES, Clough et al., 2006; Smith et al., 1999). It has also been used to calculate absorption coefficients for use in radiative transfer models for GCMs for climate applications (Mlawer et al., 1997; Iacono et al., 2008) and to train fast radiative transfer codes used in assimilation systems for Numerical Weather Prediction (NWP). Both OPTRAN (McMillin and Fleming, 1979) and OSS (Moncet et al., 2008), the fast radiative transfer models implemented in the Joint Center for Satellite Data Analysis (JCSDA) Community Radiative Transfer Model (CRTM), as well as the OPTRAN-Compact version of OPTRAN used operationally at NCEP, are trained using LBLRTM in the infrared.

The main features of LBLRTM are described in Clough et al. (2005) and also summarized here. The Voigt line shape is used at all atmospheric levels with an algorithm based on a linear combination of approximating functions. LBLRTM incorporates the continuum model MT_CKD, which includes self- and foreign-broadened water vapor as well as continua for carbon dioxide, oxygen, nitrogen, ozone and extinction due to Rayleigh scattering. Parameters from the HITRAN 2004 line database, including updates, (Rothman et al., 2005; Gordon et al., 2007) are used with a few key exceptions. Relevant exceptions for the infrared are discussed in the sections that follow. A new version of the Total Internal Partition Function (TIPS) program is used in the temperature-dependence of the line intensities (Fischer et al., 2003). Temperature dependent cross section data such as those available with the HITRAN database may be used to treat the absorption due to heavy molecules, e.g. the 
halocarbons. The algorithm implemented for the treatment of the variation of the Planck function within a vertically inhomogeneous layer is discussed in Clough et al. (1992). Line coupling in LBLRTM is modeled using a first order perturbation approach.

The version of the model used in this work is LBLRTM_v11.6. Updates in functionality since the version described in Clough et al. (2005) include the capability of computing analytic Jacobians, which are important in the retrievals of meteorological parameters, and the option of modeling absorption/emission due to clouds by way of input of an effective optical depth for a single cloud layer.

In general, errors associated with computational procedures are small - around five times less than those associated with available spectroscopic parameters. The limiting errors in spectral radiance calculations are attributable to the uncertainties in the line parameters and the line shape. (Note that most issues associated with spectroscopy are supplied externally to the LBLRTM source code in databases. The continuum and the $\mathrm{CO}_{2}$ chi function are important exceptions. These are discussed in detail in Sect. 5.1). There have been a number of recent modeling improvements to the spectroscopic parameters used by LBLRTM that have contributed significantly to the quality of the validation achieved in this work. A key development has been the utilization of line coupling for the $\mathrm{CO}_{2} \mathrm{P}$ - and R-branches. This was made possible by the extensive line coupling analysis and code developed by Niro et al. (2005) and by corresponding updates to the $\mathrm{CO}_{2}$ continuum and $\mathrm{CO}_{2}$ lineshape in LBLRTM. Prior to LBLRTM_v11.1, only Q-branch line coupling was included for $\mathrm{CO}_{2}$. (While the capability for P-, Q- and Rbranch line coupling has been available in LBLRTM for a number of years and the importance of line coupling in the P- and R-branches had been explored by Strow et al. (2003), $\mathrm{P}$ - and R-branch line coupling coefficients were not available for LBLRTM before the Niro et al. (2005) work. This issue is discussed in further detail in Sect. 5.1). Other important updates to the spectroscopic parameters are the adoption of updated water vapor line intensities from Coudert et al. (2008), the effects of which will be discussed in further detail in the results section.

\section{The IASI instrument}

The Infrared Atmospheric Sounding Interferometer (IASI) is a key payload element of the MetOp series of European meteorological polar-orbit satellites. The IASI instrument system was developed by the Centre Nationale d'Etudes Spatiales (CNES) in the framework of a cooperation agreement with EUMETSAT. The first flight model was launched in 2006 on-board the first European meteorological polarorbiting satellite, MetOp-A. The second and third instruments will be mounted on the MetOp-B and C satellites with launches scheduled in 2010 and 2015, to provide a continuous long-term data record.

IASI was designed for operational meteorological soundings with the goal of improving medium range weather forecasts. The instrument was also designed for studying atmospheric chemistry, aiming at measuring and monitoring trace gases including ozone, methane and carbon monoxide on a global scale. The measurement technique is based on passive infrared remote sensing using an accurately calibrated Fourier Transform Spectrometer operating in the $645-2760 \mathrm{~cm}^{-1}(15.5-3.6 \mu \mathrm{m})$ spectral range with $0.5 \mathrm{~cm}^{-1}$ (apodized) resolution and an associated infrared imager operating in the $800-970 \mathrm{~cm}^{-1}(10.3-12.5 \mu \mathrm{m}) \mathrm{spec}-$ tral range. The optical configuration of the sounder is based on a Michelson interferometer. The integrated infrared imager allows the co-registration of the IASI sounder with the Advanced Very High Resolution Radiometer (AVHRR) imager on-board the METOP satellite, and facilitates the processing of partly cloudy regions by a fine analysis of the properties of the clouds present in the IASI field-of-view.

The IASI total angular field-of-view is conical with a vertex angle of 3.3 degrees. It is represented by a matrix of $2 \times 2$ circular cells corresponding to a 1.25 degree angle, with centers positioned on lines and columns located at \pm 0.825 degrees from the instrument optical axis. On the ground, each cell of the analysis matrix corresponds to a circular pixel of $12 \mathrm{~km}$ diameter at a sub-satellite point. The IASI optical axis scans perpendicular to the satellite orbit track, with the optical axis moving from -47.85 degrees to +47.85 degrees in relation to the nadir, with a swath of approximately $2400 \mathrm{~km}$. Further details of the IASI instrument system are described in Challon et al. (2001).

The instrument function associated with the IASI measurements is a Gaussian with a $1 / \mathrm{e}$ point at $0.25 \mathrm{~cm}^{-1}$. The calibration and validation of the IASI Level 1 radiances is described in Blumstein et al. (2007). The assessment of the inflight performance has shown remarkably good radiometric performance (noise characteristics are similar to those measured on the ground) and excellent absolute calibration (better than 0.1 degrees Kelvin). The spectral calibration was also shown to be remarkable. (Noise characteristics are discussed further in Sect. 5.)

\section{Model/measurement comparisons: radiance closure}

\subsubsection{Comparison approach}

Space-based measurements of atmospheric constituents are often validated by means of comparisons of retrieved profiles with external sources of data, such as profiles from sondes, in situ profile measurements from aircraft and lidar observations. While such in situ and remotely sensed measurements can play an important role in validation of space-based measurements, there are a number of disadvantages associated 


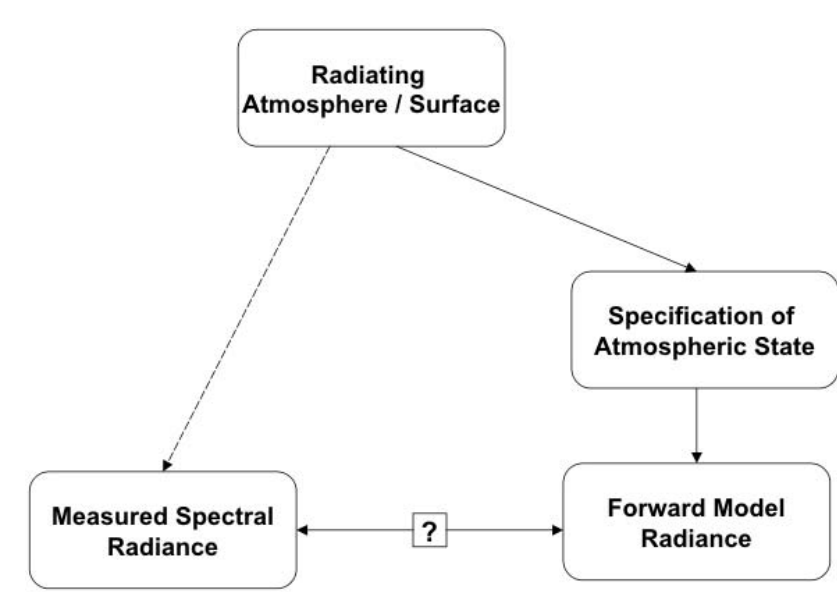

Fig. 1. "Triangle diagram" demonstrating the concept of radiance closure.

with this type of approach. One such disadvantage is the difficulty in obtaining good spatial and temporal coincidence between satellite and validation measurements. Even in targeted campaigns where great care is taken to collect in situ measurements in close coincidence with satellite overpasses, it is inevitable that the in situ measurements will not sample the atmosphere in exactly the same way that the satellite instrument does. There will always be complications associated with such comparisons, such as the difference between the points in space sampled by an in situ measurement versus the bulk air mass sampled by the satellite instrument fieldof-view or the time taken for a sonde or aircraft to ascend versus the comparatively near-instantaneous sampling of the profile by the satellite instrument. Sampling issues are particularly problematic in the validation of measurements of highly variable constituents, the most obvious example being water vapor (e.g. Shephard et al., 2008a). For example, Tobin et al. (2006) showed the short term temporal variability by performing sonde-to-sonde comparisons of radiosondes launched from the same Atmospheric Radiation Measurement (ARM) Southern Great Plains (SGP) location one hour apart. Their results showed nighttime standard deviations in the temperature profile of $0.5-1 \mathrm{~K}(1 \mathrm{~km}$ averaged layers), and variability in the water vapor profile reaching $25 \%$ (for 2-km thick layers). This same study provides insight into potential spatial variability of "near surface" atmospheric temperatures and water vapor by showing 4-km GOES products over the SGP site. In addition to the variability, the in situ measurements themselves are subject to uncertainties and/or biases. For example, humidity measurements from radiosondes have been shown to exhibit significant inconsistencies and biases compared to other instruments. Inconsistencies have also been observed between radiosonde types, even between radiosonde profiles recorded by the same type of instrument (e.g. Turner et al., 2003; Miloshevich et al., 2006; Vomel et al., 2006; Cady-Pereira et al., 2008), and between daytime and nighttime observations. Radiosonde uncertainties are particularly large in the cold, dry conditions of the upper troposphere.

Such issues raise the question of how to define truth sources that can be use to evaluate both forward models and observations utilized in retrievals and data assimilations. The current quality of modeling and measurements allows us to go beyond the capabilities usually employed in validation work. Spectral residuals (measurements minus model) of continuous or quasi-continuous radiance spectra at high spectral resolution and a line-by-line radiative transfer model provide a key to answering this question. This comparison method is known as a radiance closure study, represented in Fig. 1. As depicted in the illustration, the main elements of the radiance closure study are the radiating atmosphere/surface, the measurement of this atmosphere by an instrument, and the corresponding calculation of the same atmosphere using a radiative transfer model (Forward Model) with inputs that specify the atmospheric state (e.g. radiosondes, surface emissivity, etc). The radiance closure comes from evaluating the differences or residuals between the observations and model calculations. Any radiance residuals are then evaluated by investigating the radiance observations (e.g. instrument function), the forward model (e.g. spectroscopy), and the specification of the atmospheric state (e.g. radiosonde). The radiance closure study is used to identify and reduce the radiance residuals by carefully evaluating all components. With the high radiometric accuracy provided by current instruments and the recent improvements in spectroscopy the limiting factor in reducing the residuals is often the specification of atmospheric state (e.g. the radiosonde not sampling the same atmosphere as being measured by the satellite). It is often the case that a retrieval step is needed in the radiance closure so that the importance of external data sources in the comparison (such as radiosonde measurements) is significantly reduced, allowing greater freedom from sampling issues. The degree to which the retrieval mitigates the sampling issue depends on the non-linearity (which is a function of the variability) of the retrieval inputs). The approach adopted in this work has been to perform detailed analyses of a small number of carefully selected cases in order to work towards a physical explanation of remaining features in the spectral residuals. Further examples and details of the approach performing radiance closure studies can be found in the literature, such as Brown et al. (1998), Turner et al. (2004), and Shephard et al. (2008a).

It should also be noted that there are other commonly utilized approaches to reduce the effects of sampling and systematic errors. For example, one way to mitigate the influence of sampling issues is to gather large statistical datasets. Large-scale statistical comparisons of model/measurement differences are routinely performed by operational weather centers, such as the European Centre for Medium-range Weather Forecasts (ECMWF) for the purposes of bias monitoring (e.g. Matricardi, 2009; Masiello 
et al., 2009). Such comparisons are useful in identifying persistent discrepancies, but may not provide an obvious way to distinguish between systematic errors from the spectral measurements, the atmospheric state in the forecast model (which is influenced by the assimilation of radiosonde profiles) and the forward model.

\subsection{IASI/LBLRTM comparisons}

The comparisons presented are IASI measurements from the Joint Airborne IASI Validation Experiment (JAIVEx), a campaign based out of Ellington Field, Houston, Texas, between 14th April and 4th May 2007 (Smith et al., 2008). JAIVEx was the first US-European collaboration in the US focusing on the validation of radiances and geophysical products from MetOp-A, involving a large number of aircraft and ground-based validation measurements. Two cases were selected: one over ocean and one over land. Both cases were chosen to be clear-sky, and in proximity to radiosonde measurements. Both cases are also at nighttime, eliminating any non-local-thermodynamic-equilibrium (non-LTE) effects or solar scattering in the spectra, and also avoiding the issue of the daytime dry bias in the radiosonde humidity profiles. The ocean case is located over the Gulf of Mexico on 20 April 2007, where a number of dropsondes were deployed in the vicinity of IASI measurements. The land case is located over the ARM SGP Program site at the Southern Great Plains (SGP) in Oklahoma, on 19 April 2007. A targeted radiosonde was launched at this location to coincide with the IASI overpass. The locations of the footprints of the IASI measurements for both these cases are shown in Fig. 2. Also shown in Fig. 2 are the locations of the radiosonde drop/launch locations and the $900 \mathrm{~cm}^{-1}$ brightness temperatures from the IASI imager, indicating the location of cloudy versus clear-sky areas. For the ocean case, it can be seen that the dropsondes are all located in cloudy regions, while the chosen IASI measurements are in a clear-sky region. Therefore, the dropsonde temperature and water vapor profiles for this case would not be expected to correspond as closely to the atmosphere viewed by the chosen IASI FOVs as they would for the land case, where the clear-sky IASI radiances and radiosonde co-location is better. In each case, IASI measurements were averaged for four FOVs close to the location of the radiosonde launch/drop in order to decrease the noise in the measurement spectra for the comparisons. While this averaging reduces random measurement noise, it introduces noise due to inhomogeneity of the atmosphere and the surface.

The IASI measurements were first compared with modeled radiances using radiosonde humidity and temperature. For the ocean and land cases, the temperature profile above the top of the radiosonde was constructed by scaling tropical and US standard atmospheres respectively (Anderson et al., 1986) to match the uppermost values of the radiosonde. For the ocean case, the water vapor profile above the dropsonde
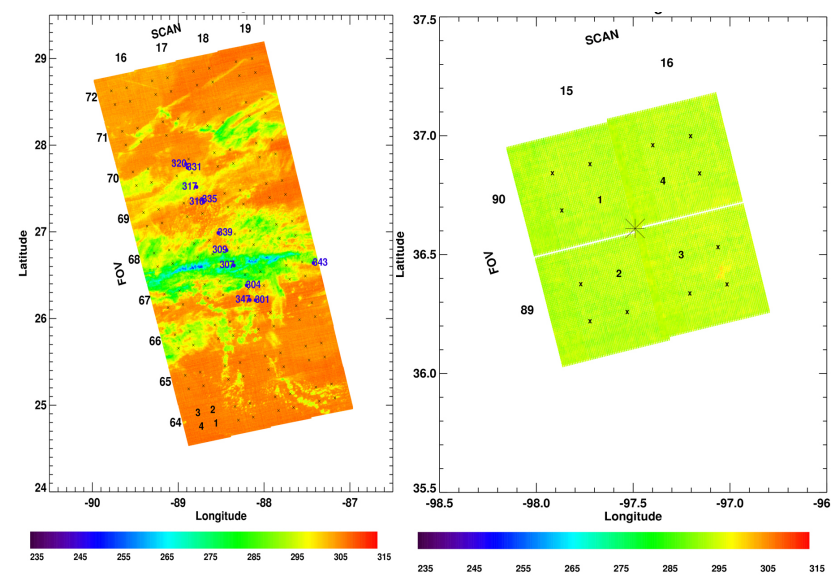

Fig. 2. Plotted are maps of IASI imager brightness temperatures showing location of IASI measurements relative to sonde locations. The numbered dots over the Gulf of Mexico (left) indicate the dropsonde locations. The star in the ARM SGP (right) case shows the location of the radiosonde launch. Overplotted on the maps are small crosses indicating the location of the IASI footprints labeled as a function of SCAN and FOV. The four pixels used in the average for the two cases are numbered in black.

was constructed by adjusting the tropical standard atmosphere to provide reasonable agreement with the IASI measured brightness temperatures. For the land case, the US standard atmosphere water vapor profile was simply added to the top of the profile. For ozone, the tropical/US (ocean/land) standard atmosphere profiles were scaled to match TOMS total column amounts. For $\mathrm{CO}_{2}$ and $\mathrm{N}_{2} \mathrm{O}$, the standard profiles were scaled to match surface observations at comparable latitude. $\mathrm{CO}$ and $\mathrm{CH}_{4}$ initial guess profiles were taken directly from the standard atmospheres, while profiles for OCS and $\mathrm{HNO}_{3}$ were taken from the mid-latitude standard atmospheres constructed by Remedios et al. (2007). All the above profiles were used as a priori in the retrievals. The surface emissivity for the ocean case was taken from the $\mathrm{Wu}$ and Smith (1997) model (zero wind speed, zero viewing angle) as described in van Delst and Wu (2000). The a priori surface emissivity used in the land case was from a previous retrieval based on eigenvector regression relations generated from infrared spectra simulated for a large ensemble of surface emissivity and atmospheric conditions (Zhou et al., 2007).

For the retrievals, an optimal estimation retrieval approach was utilized to minimize the difference between the observed IASI spectral radiances and the LBLRTM calculations of the atmospheric state subject to the constraint that the estimated state must be consistent with an a priori probability distribution for that state (Bowman et al., 2006; Clough et al., 1995; Rodgers, 2000). The spectral regions used in the retrieval of each of these parameters are shown in Table 1. Note the spectral regions used for the temperature retrievals include spectral regions in the $\mathrm{CO}_{2} \nu_{2}$ that profile the troposphere and part of the $\mathrm{CO}_{2} v 3$ region that profiles the stratosphere; 
Table 1. List of spectral regions used in retrievals.

\begin{tabular}{|c|c|}
\hline $\begin{array}{l}\text { Retrieved } \\
\text { Parameter }\end{array}$ & Spectral regions used in retrievals $\left[\mathrm{cm}^{-1}\right]$ \\
\hline $\begin{array}{l}\text { Surface } \\
\text { Emissivity }\end{array}$ & $\begin{array}{l}771.0-773.0,776.0-780.0,819.0-821.0,844.0-846.0,959.0-961.0,1088.0-1090.0, \\
1144.0-1146.0,1231.5-1232.50,1330.25-1330.75,1899.00-1901.00,2001.00-2004.00 \text {, } \\
2049.00-2051.00,2141.50-2142.50,2499.0-2501.0,2604.0-2606.0\end{array}$ \\
\hline $\begin{array}{l}\text { Surface } \\
\text { Temperature }\end{array}$ & $\begin{array}{l}\text { 817.0-823.0, 831.0-834.5, 843.0-848.0, 960.0-965.0, 1088.0-1090.0, 1144.0-1146.0, } \\
\text { 1231.5-1232.50, 1330.25-1330.75, 1899.0-1901.0, 2001.5-2005.0, 2011.5-2013.25, } \\
\text { 2030.0-2032.0, 2133.5-2135.0, 2141.50-2142.5, 2149.0-2150.0, 2171.0-2172.0, } \\
\text { 2499.0-2501.0, 2604.0-2606.0 }\end{array}$ \\
\hline Temperature & $650.0-665.0,670.0-780.0,2270.0-2375.0$ \\
\hline $\mathrm{H}_{2} \mathrm{O}$ & $\begin{array}{l}1164.50-1166.25,1173.00-1175.50,1186.00-1188.00,1197.00-1199.00,1210.75-1213.25, \\
1224.25-1226.25,1242.75-1245.25,1257.75-1261.75,1318.0-1560.0,1640.0-2020.0\end{array}$ \\
\hline $\mathrm{O}_{3}$ & $990.0-1070.0$ \\
\hline $\mathrm{CO}$ & $\begin{array}{l}\text { 2072.75-2074.0, 2094.0-2095.50, 2098.0-2099.75, 2102.25-2104.25, 2110.25-2112.50 } \\
2118.75-2120.50,2127.0-2135.0,2149.5-2151.75,2153.50-2155.50,2157.25-2159.50, \\
2164.75-2177.0,2179.0-2180.50,2182.5-2184.0,2186.0-2187.5,2189.25-2190.75, \\
2192.75-2194.25\end{array}$ \\
\hline $\mathrm{CH}_{4}$ & $\begin{array}{l}1215.25-1217.0,1227.75-1231.0,1232.75-1239.0,1240.5-1242.25,1246.0-1250.75, \\
1252.50-1259.5,1274.5-1278.25,1281.5-1284.25,1291.75-1307.50,1321.0-1323.25, \\
1325.50-1328.0,1330.50-1334.5,1345.0-1348.50\end{array}$ \\
\hline OCS & $2030.0-2085.0$ \\
\hline $\mathrm{HNO}_{3}$ & $850-925.0$ \\
\hline
\end{tabular}

the Q-branch at $667 \mathrm{~cm}^{-1}$ was excluded as the modeling for this region is under investigation (see following discussion).

\section{Results and discussion}

Figures 3 and 4 (ocean case) and Figs. 5 and 6 (land case) show: (a) the IASI measured spectra for the two cases; (b) spectra showing the variation within the four pixels averaged to obtain the measurement vector; (c) the IASI/LBLRTM comparison for the full IASI wavenumber range with initial guess input; and (d) spectral residuals after retrieval of surface temperature, atmospheric temperature, $\mathrm{H}_{2} \mathrm{O}, \mathrm{O}_{3}, \mathrm{CH}_{4}$, $\mathrm{CO}, \mathrm{OCS}$ and $\mathrm{HNO}_{3}$. Plot (e) in Figs. 3 and 5 contains the surface emissivity used in the calculations. For the land case the surface emissivity is not well known so it was retrieved.

The averaging of four FOVs decreases the noise in the measurement spectra for the comparisons, allowing easier identification of small features at high spectral resolution. However, this also has implications for the interpretation of the comparison results. It can be seen from Figs. $3 b$ and $5 b$ that there are significant variations in the atmospheric water vapor (1200 to $2000 \mathrm{~cm}^{-1}$ ), even over the relatively small geographical area covered by the four instrument FOVs. The variation in water vapor for the ocean case is greater than for the land case. It is difficult to quantify the impact of the variability based on just these two comparisons; however, comparing the magnitude of the interpixel variability presented in panels $b$ and $f$ in Fig. 3 through Fig. 6. with the overall residuals (for example in the $\mathrm{H}_{2} \mathrm{O}$ spectral region) in panels $\mathrm{d}$ and $\mathrm{h}$, we see that increased variability leads to increased residuals. Panels $b$ and $f$ in Fig. 3 through Fig. 6 also show the spectral variation of the IASI noise. A particularly striking feature in the spectra is the large variation in brightness temperature in the coldest part of the $\mathrm{CO}_{2} v_{3}$ region (2200$2500 \mathrm{~cm}^{-1}$ ) (Figs. 3 and 5).This part of the spectrum views the coldest part of the atmosphere (the tropopause region). The signal to noise here is not as good as it is for the lower wavenumber part of the spectrum that views the tropopause. Since the radiance values are small, any small variations in radiance are amplified to large variations in brightness temperature. Therefore in the analysis of this region, it is more constructive to view the residuals in terms of radiance (see Figs. 4 and 6 and Sect. 5.1).

The residuals from the initial radiosonde temperature and humidity profiles (plus US Standard atmosphere trace gas profiles) are shown in panels $\mathrm{c}$ and $\mathrm{g}$ in Fig. 3 through Fig. 6. It is clear from the magnitude of these residuals in the carbon dioxide and water vapor regions that the radiosonde profiles do not sample exactly the same atmosphere and surface 


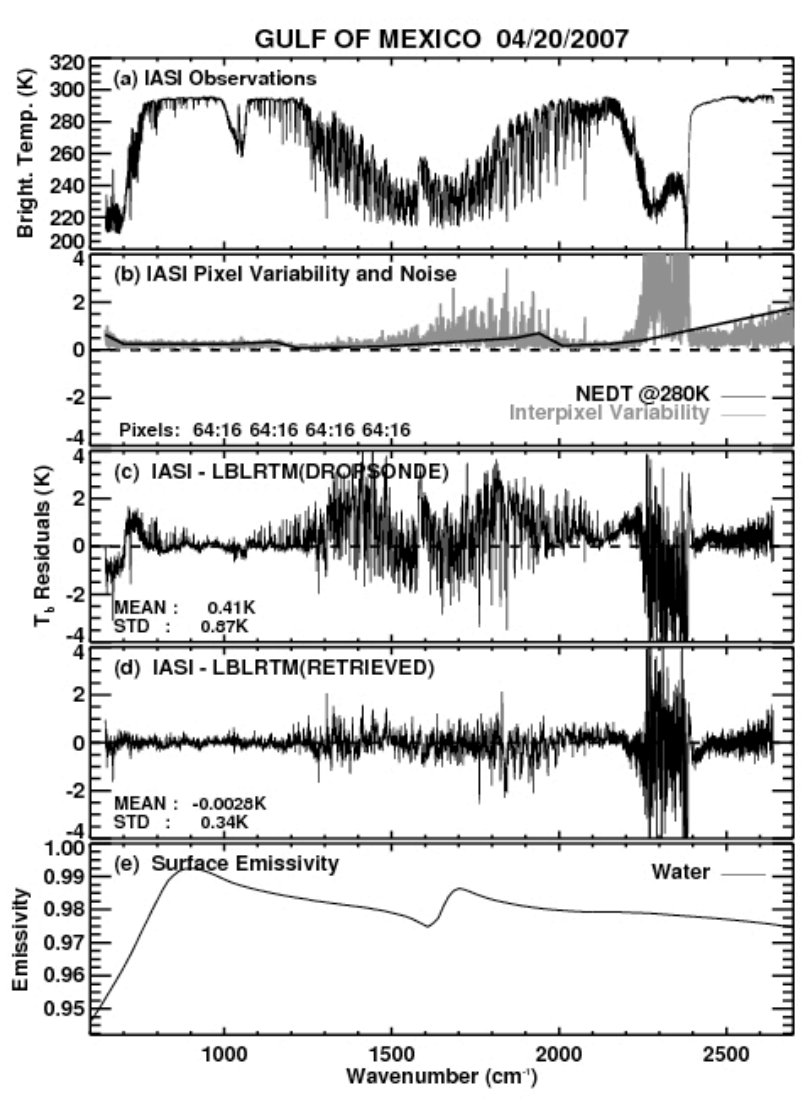

Fig. 3. (a) IASI measured spectrum in brightness temperature for the ocean case. (b) Spectra showing the variation within the four pixels averaged to obtain the measurement vector. (c) IASI/LBLRTM comparison for full IASI wavenumber range with initial guess input. (d) Comparison after retrievals of atmospheric temperature, $\mathrm{H}_{2} \mathrm{O}, \mathrm{O}_{3}, \mathrm{CH}_{4}, \mathrm{CO}, \mathrm{OCS}$ and $\mathrm{HNO}_{3}$. (e) Sea surface emissivity.

state measured by the IASI FOVs. Retrievals of temperature, surface temperature, surface emissivity (for the land case only), water vapor $\left(\mathrm{H}_{2} \mathrm{O}\right)$, ozone $\left(\mathrm{O}_{3}\right)$, methane $\left(\mathrm{CH}_{4}\right)$, carbon monoxide $(\mathrm{CO})$, nitrous oxide $\left(\mathrm{N}_{2} \mathrm{O}\right)$, carbonyl sulfide (OCS) and nitric acid $\left(\mathrm{HNO}_{3}\right)$ were performed in order to obtain the best estimate of the state measured by the IASI FOVs and the residuals examined across the full IASI spectral range. Figures $3 \mathrm{~d}$ and $5 \mathrm{~d}$ show the brightness temperature residuals after the retrievals.

Figures $3 \mathrm{e}$ and $5 \mathrm{e}$ show the emissivity used in the final residuals. For the land case, the emissivity was evaluated at the spectral points shown in Fig. 5e. Following each retrieval of temperature, water vapor and trace species, the value of the emissivity was adjusted at these spectral points to attain overall consistency across the spectrum. To provide the emissivity between these points, the spectral characteristics of the initial guess were preserved to the extent possible. In certain regions, e.g. $1750-2600 \mathrm{~cm}^{-1}$, this was not possible and linear interpolation between points was utilized. The reflectivity has been treated as 1-E, with $\mathrm{E}$ the emissivity. For
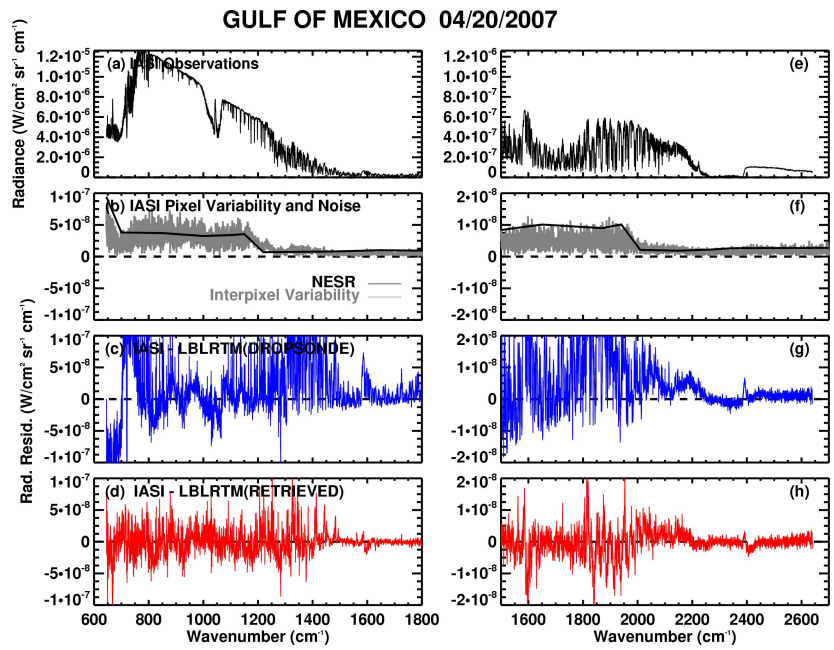

Fig. 4. (a, d) IASI measured spectrum in radiance for the ocean case. (b, e) Spectra showing the variation within the four pixels averaged to obtain the measurement vector. (c, f) IASI/LBLRTM comparison for full IASI wavenumber range with initial guess input. (d, g) Comparison after retrievals of atmospheric temperature, $\mathrm{H}_{2} \mathrm{O}, \mathrm{O}_{3}, \mathrm{CH}_{4}, \mathrm{CO}, \mathrm{OCS}$ and $\mathrm{HNO}_{3}$. Note different scales on left and right in order to better present the lower radiance at the higher wavenumbers.

the radiance calculations associated with the land case, the surface has been taken as Lambertian; for the ocean case as specular. Because of potential error associated with the surface properties for the land site, a validation over water is critical.

Features remaining in the spectral residuals after the retrievals are discussed in sub-sections by molecule. Figure 7 to Fig. 10 show temperature and water vapor profiles plus retrieval errors from ocean and land cases respectively, while Figs. 11 and 12 show the results of the other trace gas retrievals. Since the information content for minor species in the spectra is small, it is useful to examine the averaging kernels (right panels in Figs. 11 and 12). The averaging kernel, A, describes the sensitivity of the retrieval to the true state. At levels where the averaging kernel is small, the retrieval can provide little or no information. The sum of each row of $\mathbf{A}$ represents the fraction of information in the retrieval that comes from the measurement rather than the a priori (Rodgers, 2000) at the corresponding altitude, providing the retrieval is relatively linear. In order to emphasize this we have plotted the retrieved profiles only at levels where the sum of rows was greater than 0.7 . The trace of the averaging kernel matrix gives the number of degrees of freedom for signal (DOFs) from the retrieval, and thus the number of pieces of information that can be retrieved. As an illustration, the methane retrievals have approximately two degrees of freedom and thus can provide an estimate of the column amount over two broad altitude ranges, but not a profile with values at every retrieved level. 


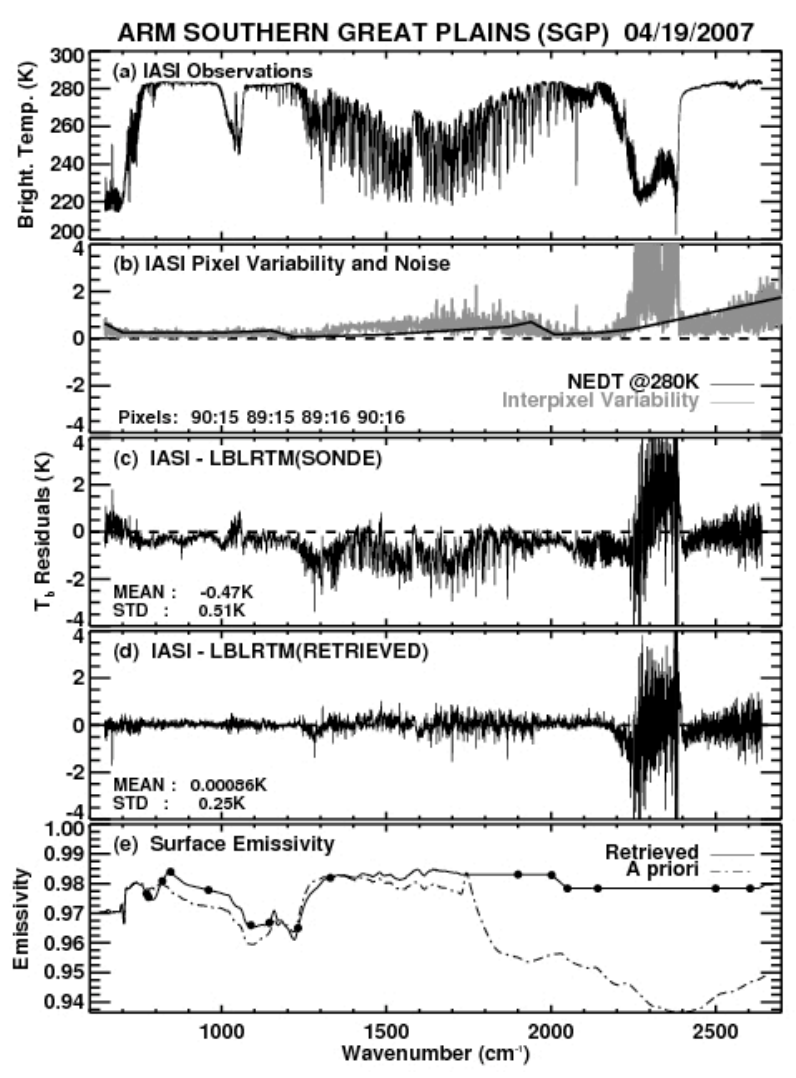

Fig. 5. (a) IASI measured spectrum in brightness temperature for the land case. (b) Spectra showing the variation within the four pixels averaged to obtain the measurement vector. (c) IASI/LBLRTM comparison for full IASI wavenumber range with initial guess input. (d) Comparison after retrievals of surface temperature, surface emissivity, atmospheric temperature, $\mathrm{H}_{2} \mathrm{O}, \mathrm{O}_{3}, \mathrm{CH}_{4}, \mathrm{CO}$, OCS and $\mathrm{HNO}_{3}$. (e) Surface emissivity.

Note that the retrievals performed for this work were primarily for the purpose of radiance closure. A number of other papers presented in this special issue will present more focused work on trace gas retrievals from IASI. Clerbaux et al. (2009) provides an overview summary of the minor gas retrievals from IASI.

\subsection{Carbon dioxide}

For purely collisional broadening in $\mathrm{CO}_{2}$ there are two dominant effects: line coupling and duration of collision, e.g. Strow et al. (2003) and references therein. Central to the development of the Lorentz line shape is the assumption of an infinitely short duration of collision between molecules - the impact approximation. In reality, the duration of the collision is finite and so in the far wings of lines, the Lorentz line shape cannot be correct. The approach to addressing this problem has been to convolve the Fourier transform of the Lorentzian in the time domain with a collision function, the width of which is the duration of collision time. A reasonable

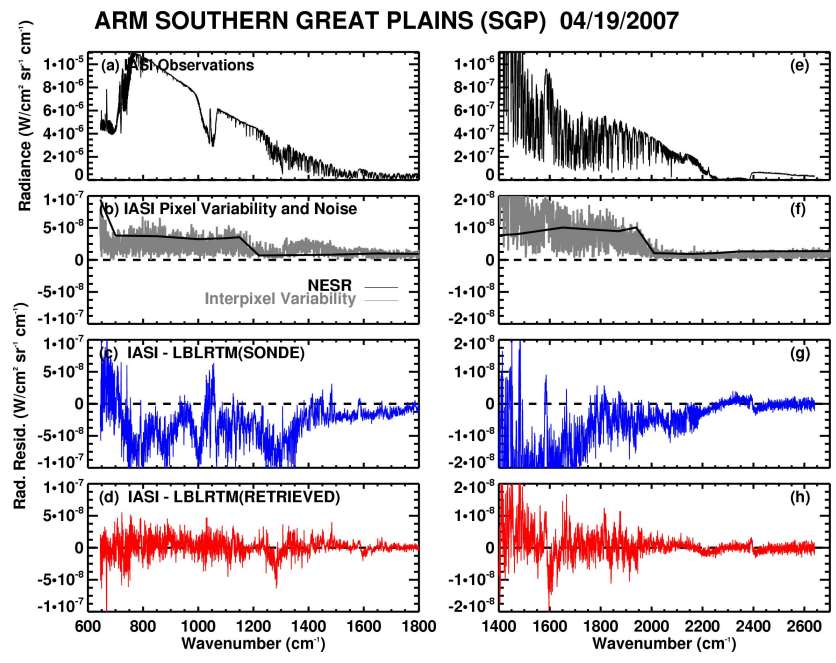

Fig. 6. (a, d) IASI measured spectrum in radiance for the land case. (b, e) Spectra showing the variation within the four pixels averaged to obtain the measurement vector. (c, f) IASI/LBLRTM comparison for full IASI wavenumber range with initial guess input. (d, g) Comparison after retrievals of atmospheric temperature, $\mathrm{H}_{2} \mathrm{O}, \mathrm{O}_{3}$, $\mathrm{CH}_{4}, \mathrm{CO}, \mathrm{OCS}$ and $\mathrm{HNO}_{3}$. Note different scales on left and right in order to better present the lower radiance at the higher wavenumbers.
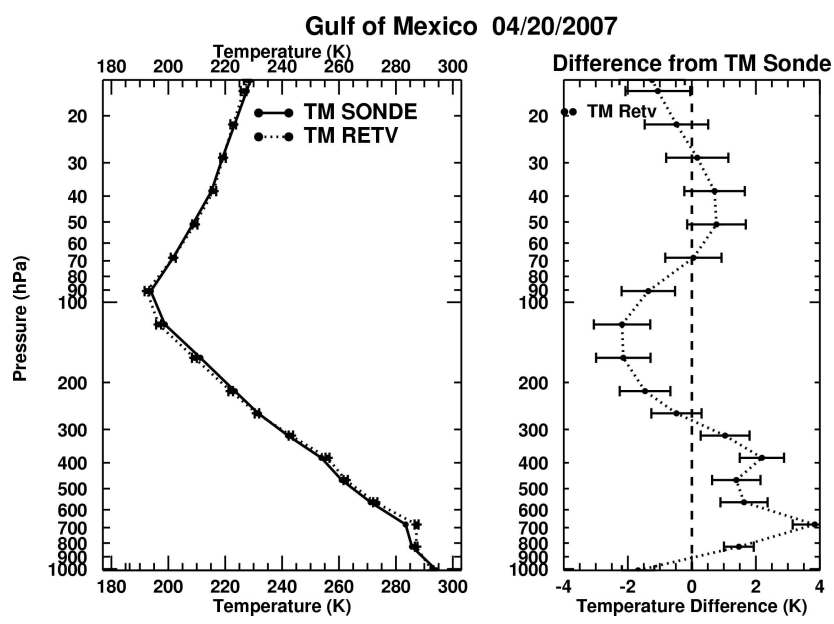

Fig. 7. Comparison plot of the sonde (a priori) and the retrieved temperature profiles for the ocean case over the Gulf of Mexico.

function to approximate the duration of collision function is the Gaussian. In the spectral domain this leads to a multiplicative spectral correction function often referred to as the chi function.

LBLRTM has long provided the capability to include line coupling using line parameter files with appropriate first (and second) order coupling coefficients at four specific temperatures. The first order approach is taken because the density scaling of the coupling parameters is consistent 


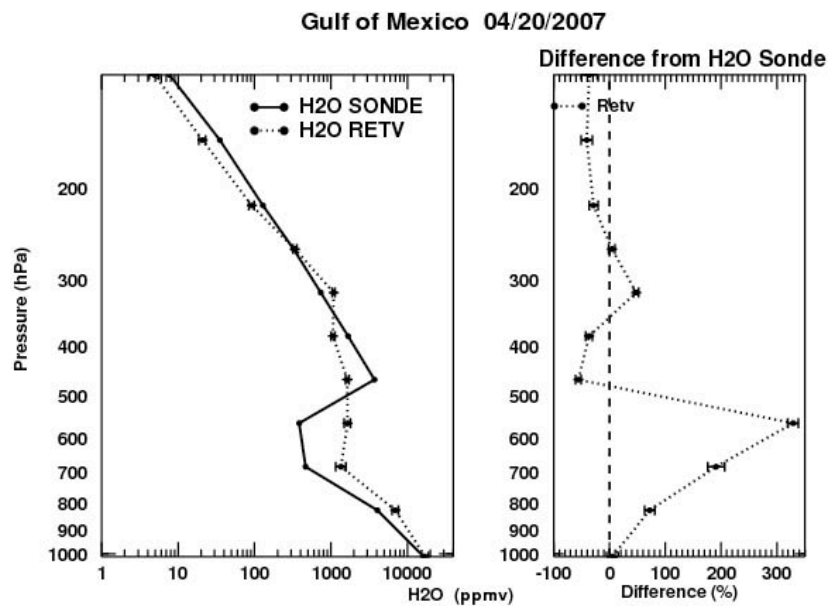

Fig. 8. Comparison plot of the sonde (a priori) and the retrieved water vapor profiles for the ocean case over the Gulf of Mexico.

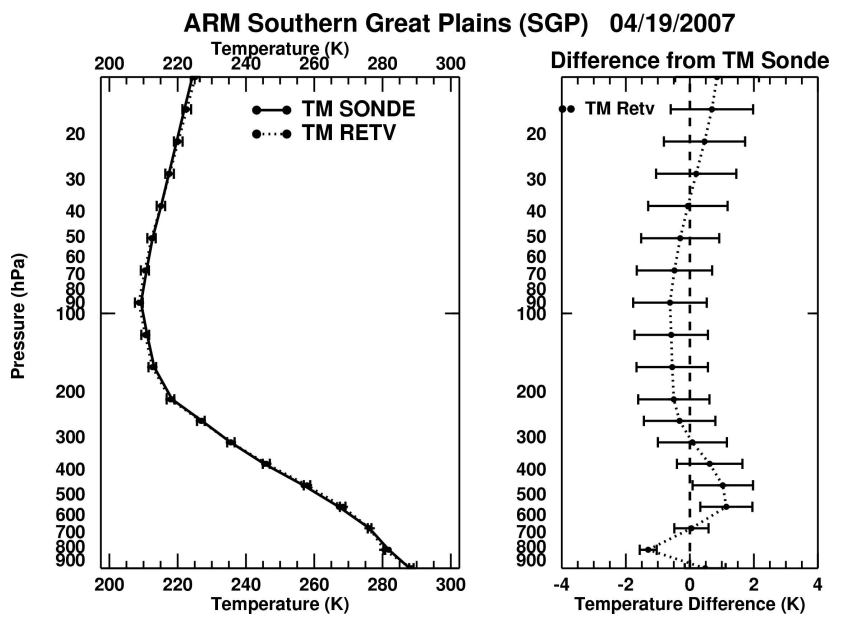

Fig. 9. Comparison plot of the sonde (a priori) and the retrieved temperature profiles for the land case over the ARM SGP site.

with the impact approximation and is easily implemented in LBLRTM. There is no additional computational cost to the inclusion of line coupling in the calculation. In this work and in our previous studies, it has been shown that in almost all cases, the transitions are sufficiently separated that the first order treatment is satisfactory. There are a few notable exceptions, for example, the $\mathrm{CO}_{2}$ Q-Branch at $596 \mathrm{~cm}^{-1}$.

In versions of LBLRTM prior to v11.1, line-coupling parameters in this format had only been available for the important Q-branches. For P- and R-transitions, both line coupling and duration of collision effects had been treated using an effective chi function. With the availability of the collision relaxation matrices for all important bands and the associated software resulting from the work of Niro et al. (2005), line parameters with the appropriate first order line coupling coefficients have been developed for all the significant $\mathrm{CO}_{2}$ transitions, including P- and R-transitions. Since P- and

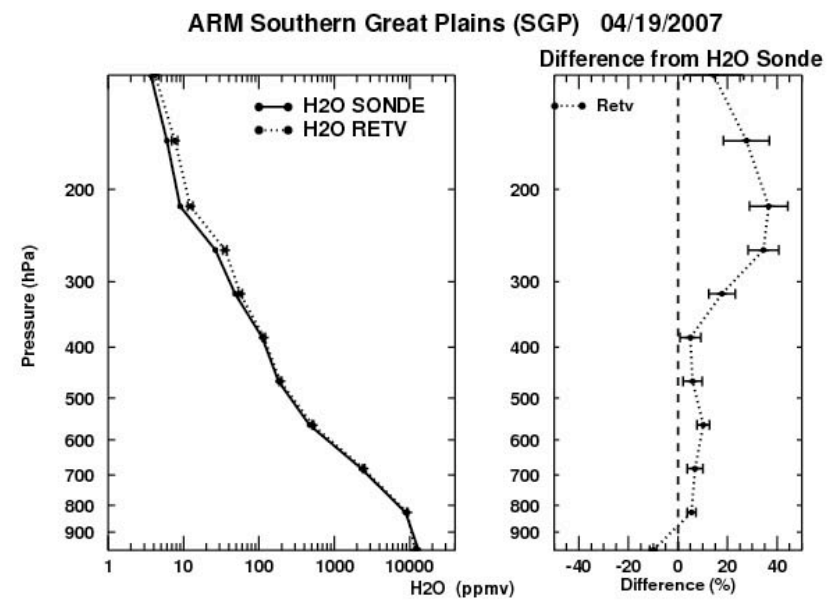

Fig. 10. Comparison plot of the sonde (a priori) and the retrieved water vapor profiles for the land case over the ARM SGP site.

R-branch line coupling coefficients are now included in the line parameter database, the chi factor in LBLRTM has been set to unity.

The continuum is inextricably linked to the line parameters and the line coupling. Therefore, when new $\mathrm{CO}_{2}$ line coupling was effectively introduced for all transitions, a new compatible continuum was required. In the development of this continuum it became clear that for $\mathrm{CO}_{2}$ with line coupling, retaining the historical definitions for the line and continuum contributions led to unacceptable discontinuities in the final continuum. In the top panel of Fig. 13, the function associated with the Lorenz contribution to the continuum is shown. The old continuum function (v11.1) has a pedestal from -25 to $25 \mathrm{~cm}^{-1}$; the new function is quadratic in the same domain with continuous derivatives at $\pm 25 \mathrm{~cm}^{-1}$. The lower panel shows the line coupling contribution over the same region. The discontinuities in the slope associated with v11.1 lead to discontinuities in the continuum, which are averted by using the continuous functions of v11.2. The resulting continuum is shown by the solid line in Fig. 14, MT_CKD v2.1 (Note that the $\mathrm{CO}_{2}$ continuum did not change between MT_CKD v2.1 and MT_CKD v2.4). In the wings of the bands the resulting continuum is much lower than that given by the impact approximation (Lorentz function) and is remarkably similar to previous versions developed using a chi factor (MT_CKD v1.3). Note that in the central band region the continuum with line coupling is greater than that based on the impact approximation. The old continuum in this region (MT_CKD v1.3) is not really comparable, since the line contribution has been changed as previously discussed. Up to this point in development, the continuum has only been calculated at $296 \mathrm{~K}$ and treated as temperature independent. A near future task will be to implement a continuum for a temperature appropriate to the tropopause and use logarithmic interpolation at intermediate temperatures. 

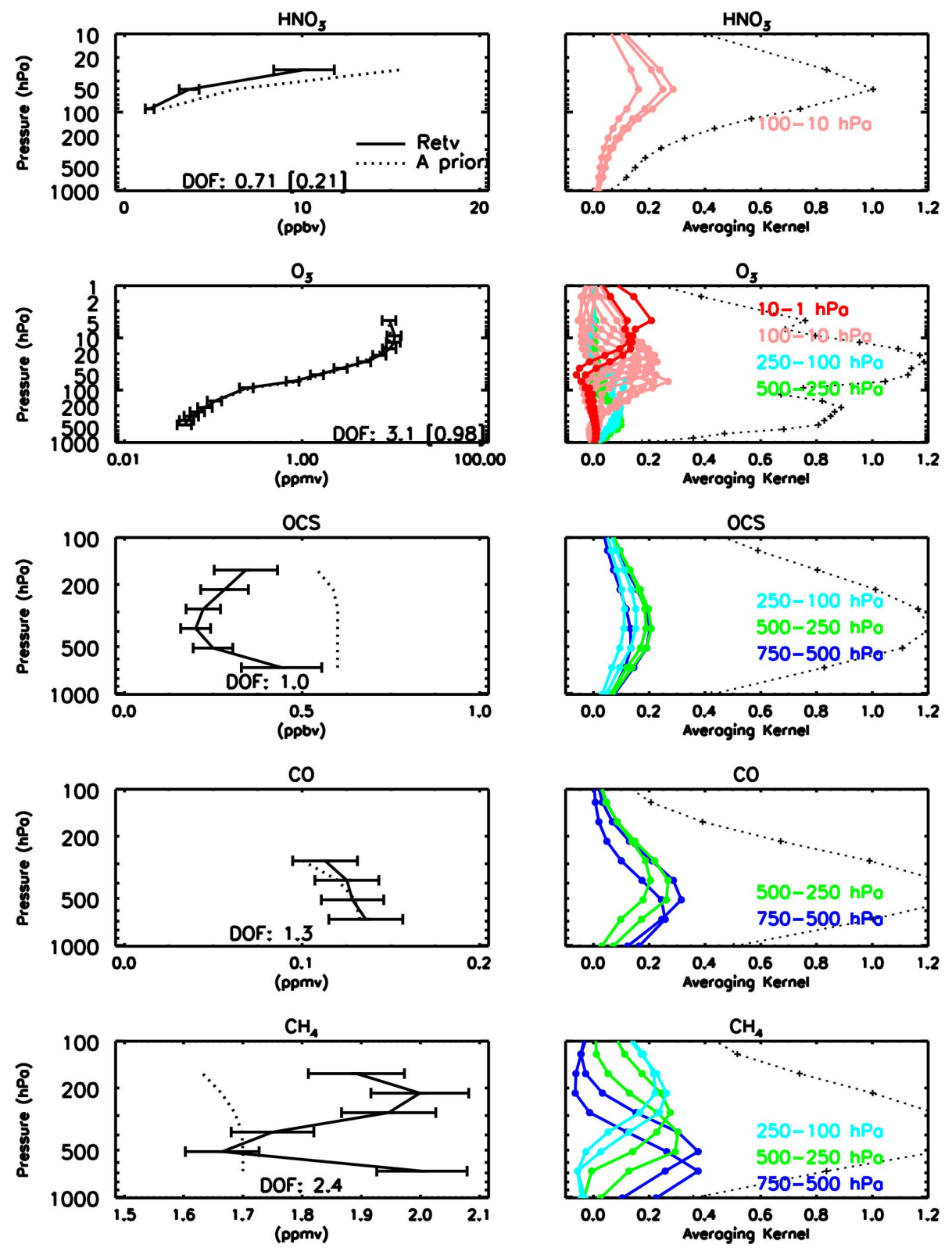

Fig. 11. Left: Tropospheric trace gas profiles and retrieval errors from the ocean case over the Gulf of Mexico. Right: Corresponding averaging kernels (in color) and sum of the rows of the averaging kernel (in black).

Of significance in the present result far from band center is the near cancellation of the continuum from the Lorentz contribution by that from the line coupling contribution. The convergence to zero of the full continuum is much more rapid than the pathological convergence associated with the Lorentz continuum alone, Fig. 14. This is a direct result of the conservative properties of the relaxation matrices developed by Niro et al. (2005) and the line coupling theory.

In general, the residuals in the $\mathrm{CO}_{2} v_{2}$ region are of the order of the measurement noise, apart from the region of the $667 \mathrm{~cm}^{-1}$ Q-branch (see Fig. 15). The brightness temperature for this Q-branch is around $1.5 \mathrm{~K}$ higher in the model than in the measurement. Even at the spectral resolution provided by the IASI instrument, the spectral points spanning the $667 \mathrm{~cm}^{-1}$ Q-branch sample a wide vertical range, from around $100 \mathrm{hPa}$ to the top of the atmosphere. The upper panel of Fig. 16a shows the monochromatic LBLRTM modeled brightness temperatures together with the IASI measurement. This figure shows both the wide range of atmospheric temperatures sampled by the few spectral points here, and the extent of the spectral structure in the $\mathrm{CO}_{2}$ spectrum in this region relative to the IASI spectral resolution. With the monochromatic spectrum the brightness temperature can be followed from the tropopause to the stratopause on to the 

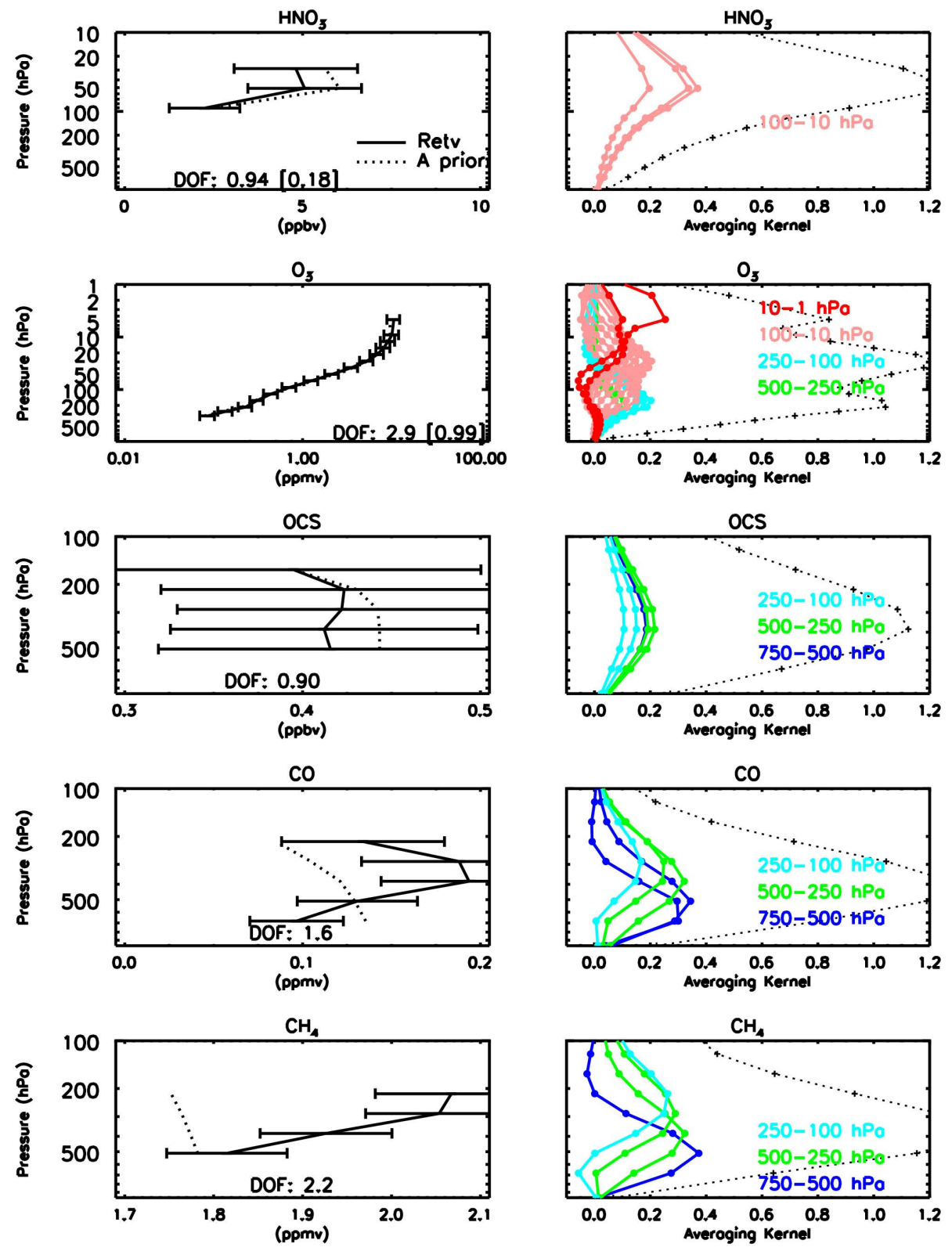

Fig. 12. Left: Tropospheric trace gas profiles and retrieval errors from the land case over the ARM SGP site. Right: Corresponding averaging kernels (in color) and sum of the rows of the averaging kernel (in black).

temperature associated with the top of the profile. Figure 16b shows the IASI-LBLRTM residuals in this region. The large residual at the $667 \mathrm{~cm}^{-1}$ Q-branch is judged to be related to errors in the temperature profile in the upper stratosphere on into the mesopause, including possible premature truncation of the profile. These altitudes are higher than those sampled by the $v_{3}$ region. However, it remains possible that there is an issue with the modeling of the Q-branch lines (e.g. line positions). Figure 16c shows the slight difference in using the 1 st order compared with the exact line coupling formulation does not account for the residuals in the Q-branch lines. This plot also contains a comparison between brightness temperatures calculated with ("exact") and without ("Voigt") line coupling.

Figure 17 shows the radiance spectrum and residuals in the $\mathrm{CO}_{2} v_{3}$ band for the land case. Since the radiance values are so low, any small variations in radiance are amplified to large variations in brightness temperature. It can be clearly seen by looking at the large brightness temperature variations in this region in Figs. 3 and 5 that it is constructive to look at the residuals in terms of radiance for this region. The overall shape of the residuals is the same for both the 

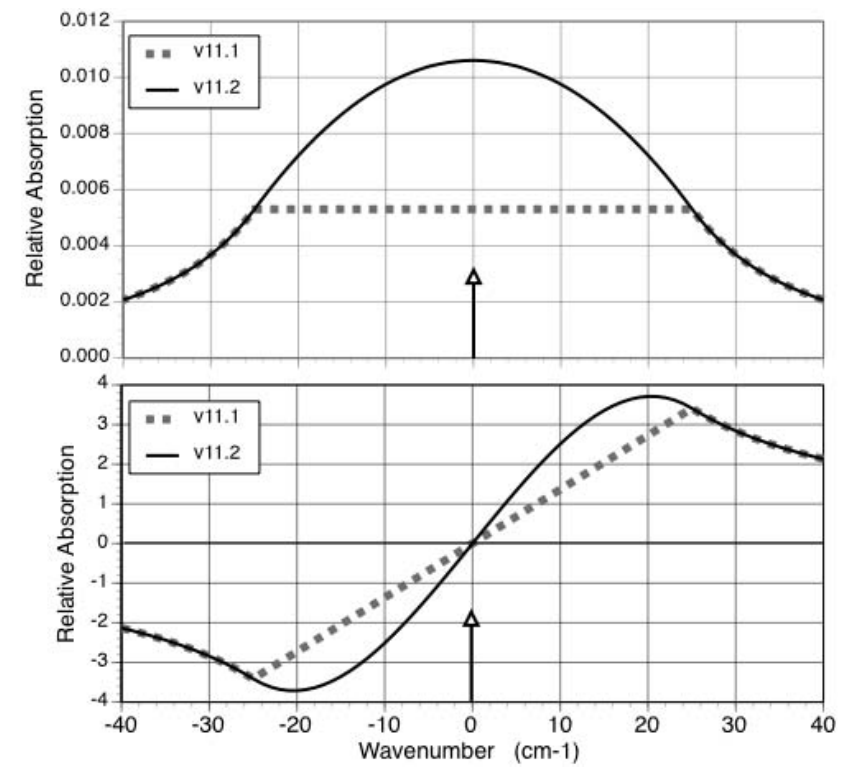

Fig. 13. The top panel represents the function associated with the Lorentz contribution to the continuum. The old system (v11.1) has a pedestal from -25 to $25 \mathrm{~cm}^{-1}$; the new function is quadratic in the same domain. The lower panel shows the line coupling contribution over the same region. The discontinuities in the slope associated with v11.1 lead to discontinuities in the continuum, which are averted by using the continuous functions of v11.2.

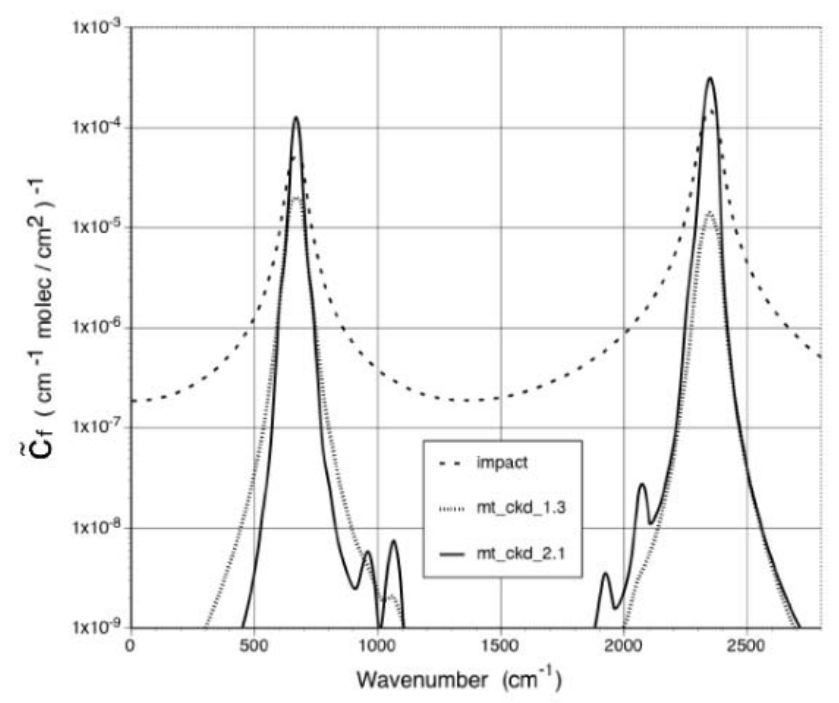

Fig. 14. Plots of LBLRTM $\mathrm{CO}_{2}$ continuum models: The dashed line is the continuum from the impact approximation (assumes collisions occur instantaneously). The dotted line is the $\mathrm{CO}_{2}$ continuum in MT_CKD v1.3 based on an effective chi factor. The solid line is the MT_CKD v2.1 continuum based on first order line coupling with parameters from Niro et al. (2005). Note that the $\mathrm{CO}_{2}$ continuum did not change between MT_CKD v2.1 and MT_CKD v2.4).

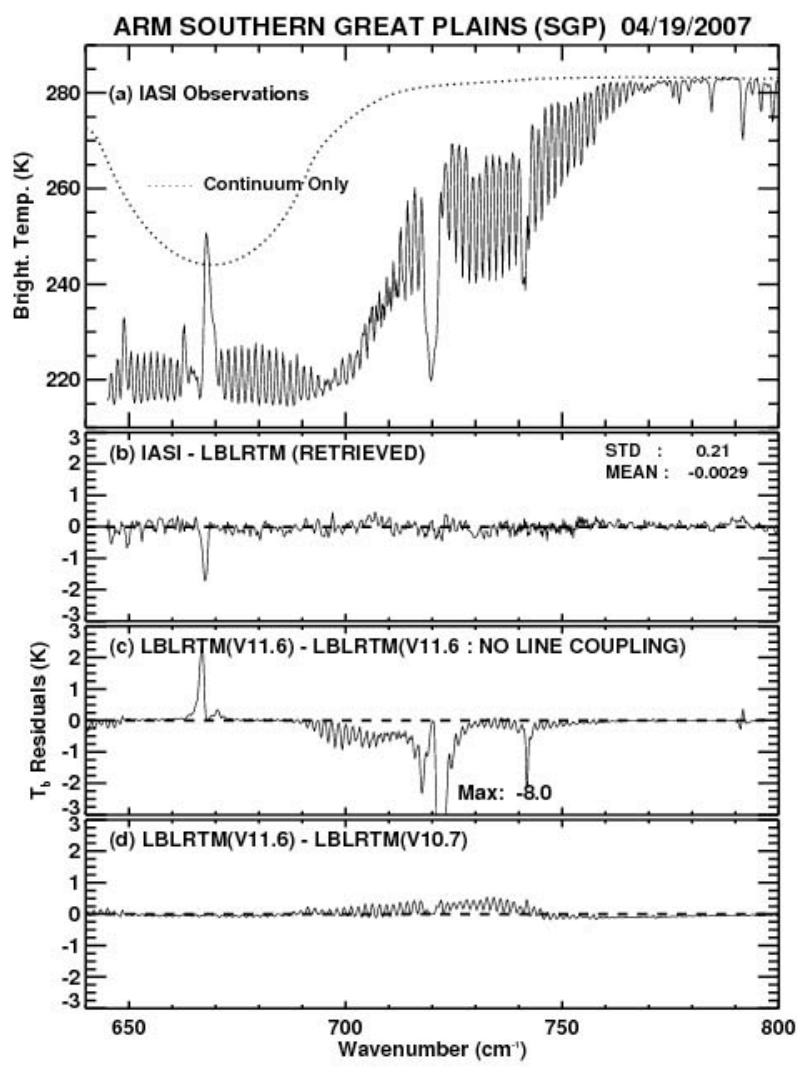

Fig. 15. (a) IASI brightness temperature spectrum in the $\mathrm{CO}_{2} v_{2}$ region $\left(640-800 \mathrm{~cm}^{-1}\right)$ for the land case, showing the contribution from the continuum. (b) IASI/LBLRTM final residuals. (c) Model/model brightness temperature differences: LBLRTM v11.6 ( $\mathrm{P}, \mathrm{Q}$, and $\mathrm{R}$ line coupling, MT CKD v2.1 and chi=1) minus LBLRTM V11.6 (no line coupling, MT CKD v2.1, and chi=1). (d) Model/model brightness temperature differences: LBLRTM v11.6 ( $\mathrm{P}, \mathrm{Q}$, and $\mathrm{R}$ line coupling, MT CKD v2.1 and chi=1) minus LBLRTM v10.7 (with old Q-branch line coupling, old continuum and the older chi factor).

land and ocean cases. While the line coupling updates have resulted in marked improvements in LBLRTM/measurement residuals, there are remaining features in the residuals in the general $v_{3}$ region of $\mathrm{CO}_{2}$ that are not consistent with optimal temperature profiles associated with $\mathrm{v}_{2}$. The negative radiance residuals in the low frequency side of the $\mathrm{v}_{3}$ region, 2170 to $2270 \mathrm{~cm}^{-1}$, associated with $\mathrm{N}_{2} \mathrm{O}$ and $\mathrm{CO}_{2}$ radiation from the surface to the tropopause corresponds to a residual in brightness temperature of approximately $-0.5 \mathrm{~K}$. Preliminary analyses suggest that these negative residuals are associated with errors in the $\mathrm{CO}_{2}$ line intensities in this region. The $\mathrm{CO}_{2} v_{3}$ line intensities and positions have remained the same through HITRAN 2004, HITRAN 2000, and HITRAN 96 (Rothman et al., 1998). These data were mainly derived using the DND (Direct Numerical Diagonalization) method (Watson and Rothman, 1992). However, more recently an 

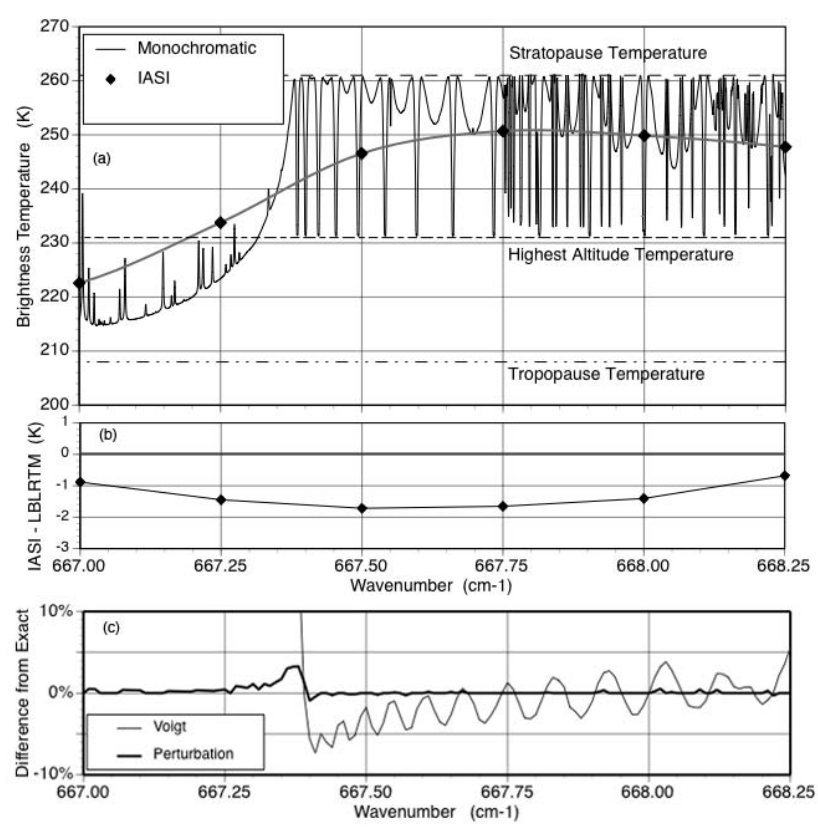

Fig. 16. Plot (a) shows the monochromatic brightness temperatures in the region of the $667 \mathrm{~cm}^{-1} \mathrm{Q}$-branch. The $1 / \mathrm{e}$ value of the IASI Gaussian instrument function is at -0.25 and +0.25 of the nominal wavenumber value, i.e. the plot grid lines. The temperatures at the tropopause, highest altitude in the profile and stratopause are shown for reference. Plot (b) shows the IASI-LBLRTM residuals over this spectral domain. Plot (c) shows the difference between the exact line coupling calculation and the calculations using 1st order perturbation theory (thick "Pertubation" line) and no line coupling Voigt line shape (thin "Voigt" line).

analogous method based on global fits of observed frequencies and line intensities using the effective operator approach (Tashkun et al., 1998, 1999a) was developed and used to generate new line parameters for the four most abundant isotopic species of carbon dioxide. These frequencies and intensities are available through the Carbon Dioxide Spectroscopic Databank (CDSD) (Tashkun et al., 1999b; Perevalov and Tashkun, 2008). The CDSD line parameters were adopted for use in the forward model for the Michelson Interferometer for Passive Atmospheric Sounding (MIPAS), after studies by Flaud et al. (2003) showed them to provide improved consistency in MIPAS stratospheric limb temperature retrievals. Our recent preliminary work (not shown) suggests that the Perevalov and Tashkun (2008) line parameters may significantly improve the residuals in this important region.

Residuals associated with the modeling of the $\nu_{3}$ bandhead at $2385 \mathrm{~cm}^{-1}$, though greatly improved with the new continuum, are not resolved. It has long been assumed that the strong sub-Lorentzian behavior in the $2385 \mathrm{~cm}^{-1}$ region of $\mathrm{CO}_{2}$ was due to both line coupling and duration of collision effects. More recently (this work, Strow et al., 2003, and references therein), it has become clear that the dominant effect is due to line coupling, although duration of

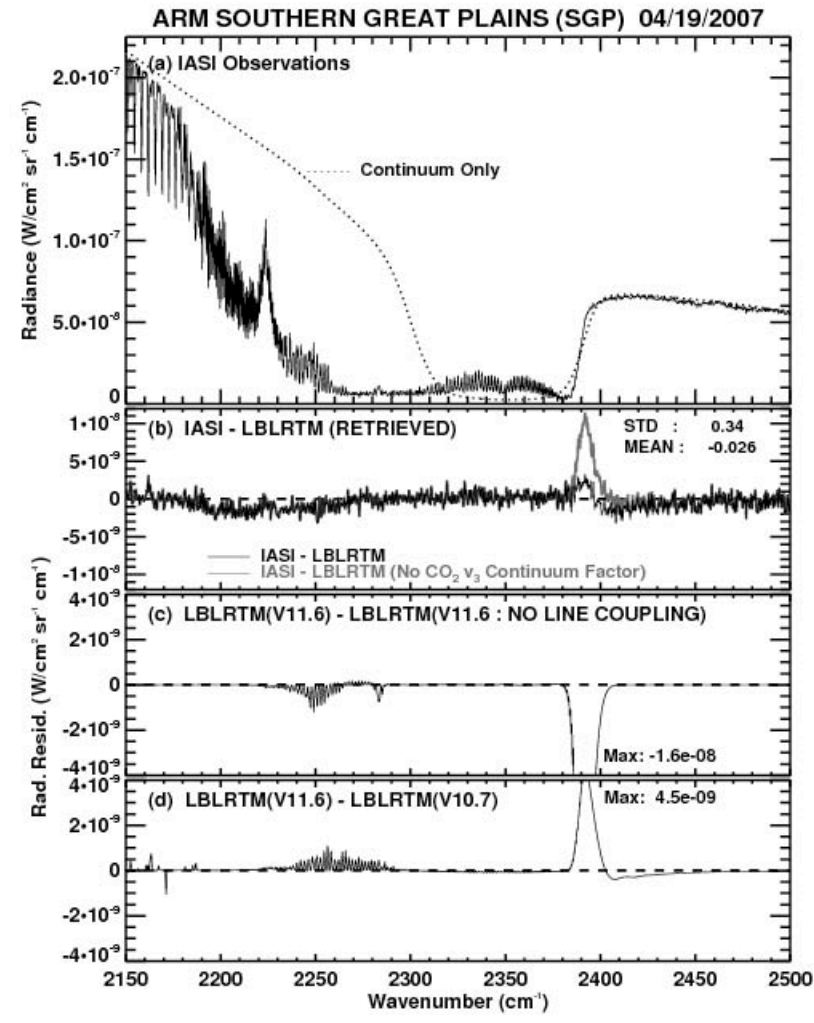

Fig. 17. (a) IASI radiance spectrum in the $\mathrm{CO}_{2} n_{3}$ region $\left(2150-2500 \mathrm{~cm}^{-1}\right)$ for the land case, showing the contribution from the continuum. (b) IASI/LBLRTM final radiance residuals (solid line), also showing the residual resulting from a version of the continuum that does not include an empirical correction around $2385 \mathrm{~cm}^{-1}$ (dash-dotted line). (c) Model $/$ model radiance differences: LBLRTM v11.6 (P, Q, and R line coupling, MT_CKD v2.4, and chi=1) minus LBLRTM V11.6 (no line coupling, MT_CKD v2.4, and chi=1). (d) Model/model radiance differences: LBLRTM v11.6 (P, Q, and R line coupling, MT_CKD v2.4, and chi=1) minus LBLRTM v10.7 (old Q-branch line coupling, old continuum and the older chi factor).

collision effects are still under investigation. The gray line in Fig. $7 \mathrm{~b}$ shows the large positive residual that results from a continuum calculated using the current line parameters and line coupling coefficients, without any modification. In order to obtain a more acceptable but imperfect result, an empirical modification has been applied for the operational version of LBLRTM. Intensive efforts are currently underway to resolve this longstanding problem. It has been demonstrated that performing the exact numerical calculation for the line coupling has no impact on the result. Modification to the relaxation matrix and the introduction of a non-unity chi factor for duration of collision effects are being explored.

The negative spectral residual features to the right of the $\mathrm{CO}_{2} \quad \nu_{3}$ bandhead $\left(2385 \mathrm{~cm}^{-1}\right)$ are observed for both the land and ocean cases. While there are some uncertainties in the surface emissivity for the land case, the sea surface 
emissivity is modeled well for the nadir ocean case. Therefore, the fact that the same residual feature is seen here for both cases provides some confidence that the surface emissivity is not the cause of the negative residual to the right of the bandhead. In fact, the consistency of the residual fit between 2450 and $2600 \mathrm{~cm}^{-1}$ in both cases provides support to the values of land surface emissivities shown for this spectral region. Recent analysis from Atmospheric Radiation Measurement (ARM) ground-based Atmospheric Emitted Radiation Interferometer (AERI) observations, which measures downwelling radiances with no surface contribution, show that this residual signature is dominated by $\mathrm{CO}_{2}$ line shape (E. Mlawer, personal communication, 2009).

\subsection{Water vapor}

The final residuals in the water vapor region in Figs. $3 \mathrm{c}$ and $5 \mathrm{c}$ are somewhat larger than expected, particularly for the ocean case. The large residuals in the ocean case should not be due to the fact that the dropsonde measurements used as initial guess and a priori were located in somewhat different atmospheric conditions than the IASI measurement. As stated in the introduction, an advantage of the radiance closure study is that it should reduce the dependence of any conclusions about "truth" on external data sources such as radiosondes. Rather, it is likely that the large magnitude of the residuals for the ocean case compared to the land case is related to the variability of the water vapor within the four FOVs averaged to obtain the IASI measurement spectrum. (See Fig. 3b compared to Fig. 5b.) Each of the four FOVs used in the average has a footprint diameter of $12 \mathrm{~km}$. Even within the area of one FOV, one can expect significant variability in the water vapor. For examples, see Shephard et al. (2008a) and Tobin et al. (2006).

The residuals shown in Figs. 3 and 5 and the water vapor profiles in Figs. 7 and 9 are the result of using water vapor line intensities and positions from Coudert et al. (2008) (subsequently referred to as Coudert) with other line parameters from the HITRAN 2004 database with relevant updates up to December 2008 (including the updates to the line widths described in Gordon et al., 2007.) The newer Coudert line intensity work involved an extensive re-fitting of existing laboratory measurements, as well as some new measurements. These newer line intensities used in the study are 5-7\% stronger than the corresponding HITRAN 2004 values for the stronger lines. The existing HITRAN 2004 line positions and intensities for this water vapor band were based on the work of R. Toth (Rothman et al., 2005) and were a great improvement on the previous water vapor parameters in this region. $\mathrm{R}$. Toth has recently reanalyzed his lab data plus new data and has concluded that his previous line intensity values were off by up to $7 \%$ for the strongest lines, and his new results agree to better than $1 \%$ with Coudert (R. Toth and L. Brown, personal communication, 2009). Figure 18 demonstrates the impact of the line intensity differences. Figure 18a shows
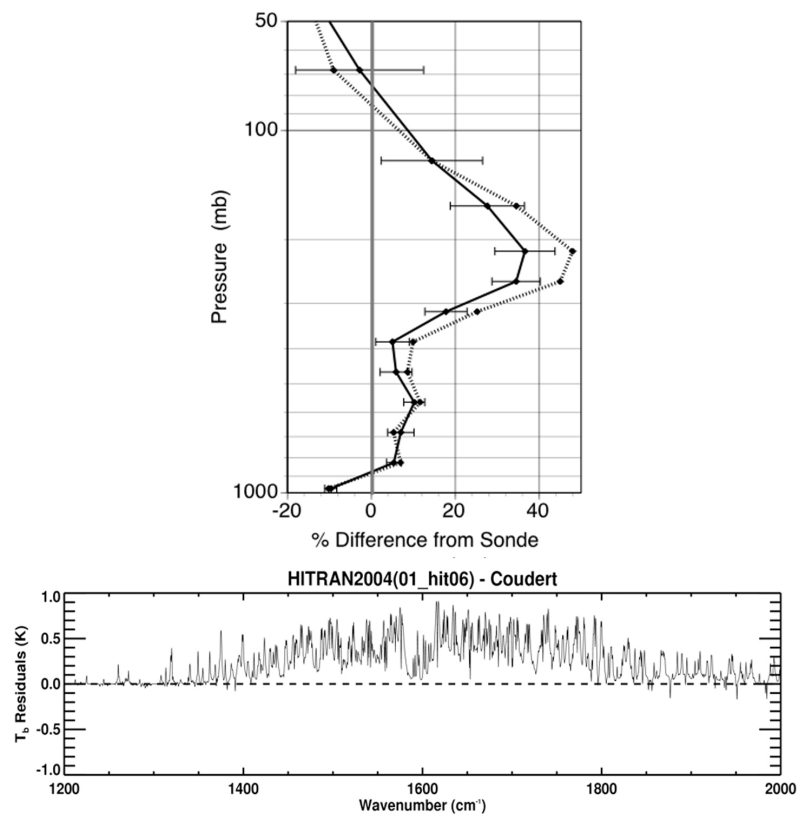

Fig. 18. Plot (a) shows the differences in the retrieved profile resulting from the Coudert water vapor line strengths. The dotted line is the difference from the radiosonde using the HITRAN2004 water vapor line parameters in the retrieval, and the solid line is the difference from the radiosonde profile using Coudert water vapor lines in the retrieval (note the $\sim 10 \%$ difference in the upper troposphere). Plot (b) shows the model/model brightness temperature differences in the water vapor band resulting from the substitution of the HITRAN 2004 water vapor line strengths for the Coudert strengths for the land case.

the difference in the retrieved profile for the IASI land case (Fig. 10) obtained by using the two different sets of line parameters. It can be seen that the difference in the line parameters results in a difference of around $10 \%$ in the retrieved upper tropospheric water vapor for this case (difference between the dark solid line and the lighter dotted line). This is to be expected since the line intensities are directly proportional to the water vapor amount. Figure $18 \mathrm{~b}$ shows the model-model differences between LBLRTM runs using the HITRAN 2004 water vapor line intensities and positions and Coudert's, using the same atmospheric state for both runs. The different sets of line parameters result in brightness temperature differences of up to $1 \mathrm{~K}$ near the $\mathrm{H}_{2} \mathrm{O} \nu_{2}$ band center (stronger lines).

Comparisons (not shown) have also been made between LBLRTM and AIRS for clear-sky, nighttime cases from the AIRS Phase 1 validation dataset over the ARM Tropical Western Pacific (TWP) site. (See Strow et al., 2006, and Tobin et al., 2006) for further details of this AIRS dataset and the "best estimate" profiles used as input to the radiative transfer code.) These AIRS comparisons (not shown) also demonstrate that Coudert's line parameters agree better with "best estimate profiles" constructed from multiple radiosonde launches collocated with AIRS overpasses. 

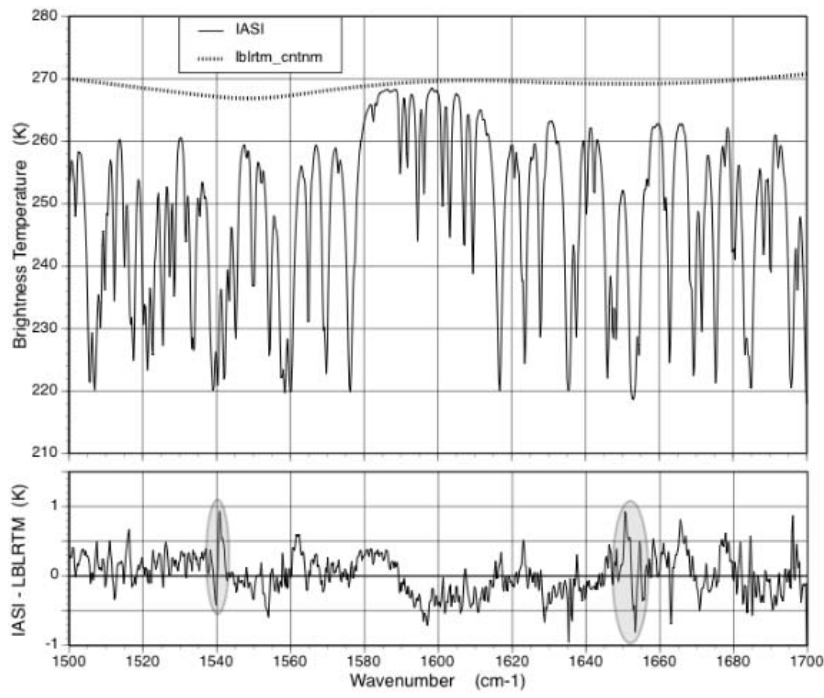

Fig. 19. Top: IASI measured brightness temperatures in the water vapor band for the land case, also showing the contribution from the water vapor continuum in this region. Bottom: IASI-LBLRTM residuals after the retrieval, showing the residual feature in the band center and the residual signature of water vapor line coupling for two pairs of water vapor lines at 1540 and $1655 \mathrm{~cm}^{-1}$.

The water vapor band contains a wealth of information on temperature as well as humidity. If the temperature information from the water vapor band is inconsistent with the temperature information from the carbon dioxide bands (as it will be if there are systematic errors in the water vapor spectroscopy) then for joint retrievals and assimilation purposes, it is better to leave out the water vapor channels for temperature in order to avoid degrading the forecast (see, for example, Joiner et al., 2007, Shephard et al., 2008b). Therefore, improvements to consistency between the spectroscopy for different molecules provides the opportunity to efficiently utilize the information contained in these type of hyperspectral sensors rather than discarding information. This will have particular importance when combining observations from different spectral regions.

Radiosonde humidity measurements are widely acknowledged to exhibit large biases, particularly in cold, dry conditions such as those observed in the upper troposphere. The measurements used here were taken at nighttime, and so there should be no radiation dry bias in the humidity profile, but other issues could remain. In addition, since atmospheric water vapor is so highly variable in space and time, there is no guarantee here that the atmosphere sampled by the in situ radiosonde measurements provides a true representation of the atmosphere as seen by IASI. It is interesting to note that the retrieval using the Coudert line parameters results in a water vapor profile that is closer to the profile measured by the radiosonde. Since radiosonde humidity profiles are assimilated in NWP models, if the line parameters bring the forward-modeled radiances from the radiosonde closer towards consistency with the satellite measurements, then this ought to result in fewer problems in the assimilation of water vapor channels. However, since the radiosonde profile should not necessarily be regarded as the truth, the profile retrievals themselves cannot be used to determine which set of line parameters is more accurate. Ordinarily, we expect to obtain information about "truth" from the radiance closure process, by examination of the residuals after retrievals using the alternative sets of spectroscopic data. The standard deviation in the residuals in the water vapor band resulting from the retrievals using the Coudert intensities and positions are very slightly smaller in magnitude than the standard deviation of the residuals resulting from the HITRAN 2004 water vapor line parameters (not shown), but the difference is not compelling. All the evidence shown here, plus the new laboratory results from $\mathrm{R}$. Toth, would seem to be in favor of the Coudert $\mathrm{H}_{2} \mathrm{O}$ line parameters, but the results are not clear-cut when there is no good truth available.

It has been established that changing the line intensities does not necessarily impact the magnitude of the retrieval residuals. The remaining residual features are associated mainly with the atmospheric variability of water vapor and with uncertainties in the line widths, pressure shifts and line coupling.

Figure 19 shows closer views of the water vapor band for the SGP land case. Residual features include the signatures of two pairs of line-coupled water vapor lines: two P-branch lines: (1 $\left.\begin{array}{lll}1 & 0 & 1\end{array}\right)<-\left(\begin{array}{lll}2 & 1 & 2\end{array}\right)$ mixing with $\left(\begin{array}{lll}2 & 1 & 2\end{array}\right)<-\left(\begin{array}{ll}3 & 0\end{array}\right.$ 3 ) at 1539.061 and $1540.300 \mathrm{~cm}^{-1}$, respectively; and two Rbranch lines: $\left(\begin{array}{lll}3 & 0 & 3\end{array}\right)<-\left(\begin{array}{lll}2 & 1 & 2\end{array}\right)$ mixing with $\left(\begin{array}{lll}2 & 1 & 2\end{array}\right)<-\left(\begin{array}{lll}1 & 0 & 1\end{array}\right)$ at 1652.400 and $1653.267 \mathrm{~cm}^{-1}$, respectively. Line coupling effects for these line pairs have been measured by Brown et al. (2005), but line coupling coefficients for water vapor are not currently included in the line parameter database supplied with LBLRTM. The effect is small, but the fact that the water vapor line coupling signature can be identified in the residuals is testament to the high quality of the IASI measurements.

The MT_CKD_2.4 water vapor continuum provides good agreement with IASI measurements, apart from in the center of the water vapor $v_{2}$ band. Figure 20 shows a close-up of the residuals in the band center. There is no continuum that will fit both the IASI data and the smoothness constraints imposed by the MT_CKD continuum formulation.

Note that these cases, with column water vapor values of around $1.5 \mathrm{~cm}$, are not particularly moist and therefore do not provide a stressing test of the water vapor continuum. The evaluation of the water vapor continuum is best done from the surface looking up (e.g. Turner et al., 2004).

Ongoing work in this region will involve an in-depth evaluation of the line widths, the temperature dependence of the widths and pressure shifts, but the issue of the variability of the water vapor within the satellite FOVs will inevitably complicate this analysis. 

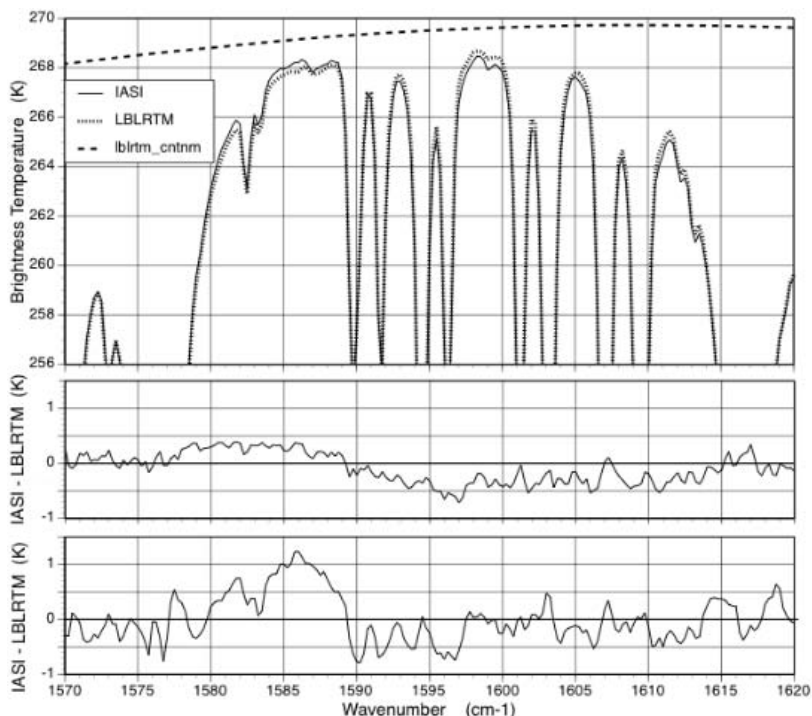

Fig. 20. Brightness temperatures and residual spectra for the water vapor band center, showing the residual feature associated with the water vapor continuum. Top: Measured and modeled brightness temperatures for the land case. Middle: Residuals for the land case. Bottom: Residuals for the ocean case.

\subsection{Trace gases}

The IASI spectra have been shown to contain information on a range of trace gas molecules. While in-depth analyses of retrievals of trace gases are covered by other papers in this ACP special issue and are outside the scope of this work, the retrievals performed here are mainly for the purposes of radiance closure. However, they do provide further examples of IASI's capability for measuring trace gases such as ozone, methane, and carbon monoxide. In addition, the high IASI SNR and sufficient spectral resolution in conjunction with the accurate LBLRTM calculations demonstrate the potential for the IASI detection of minor trace gas species with weak atmospheric signatures (less than $1 \mathrm{~K}$ in brightness temperature) in nadir observations, such as $\mathrm{HNO}_{3}$ and OCS.

Figure 21 contains IASI observations of ozone, methane, and carbon monoxide, all of which are easily seen in the IASI spectrum in plots (a), (c) and (e). The dark lines in the brightness temperature (IASI-LBLRTM) residual plots (b), (d) and (f) are from the retrieved profiles of all the species. The overplotted light gray line on these (IASI-LBLRTM) residual plots is generated from the a priori profile for the species of interest in that plot. There are a number of interesting points shown on these trace gas spectral plots.

For ozone, Fig. 21b shows that the ozone residuals in the JAIVEx IASI/LBLRTM residuals (from the HITRAN 2004 ozone parameters) are generally good, although there is a shape to the final residuals that is common to both cases (only the land case has been shown here in the close-up plot). It is not very pronounced in these two cases and might be
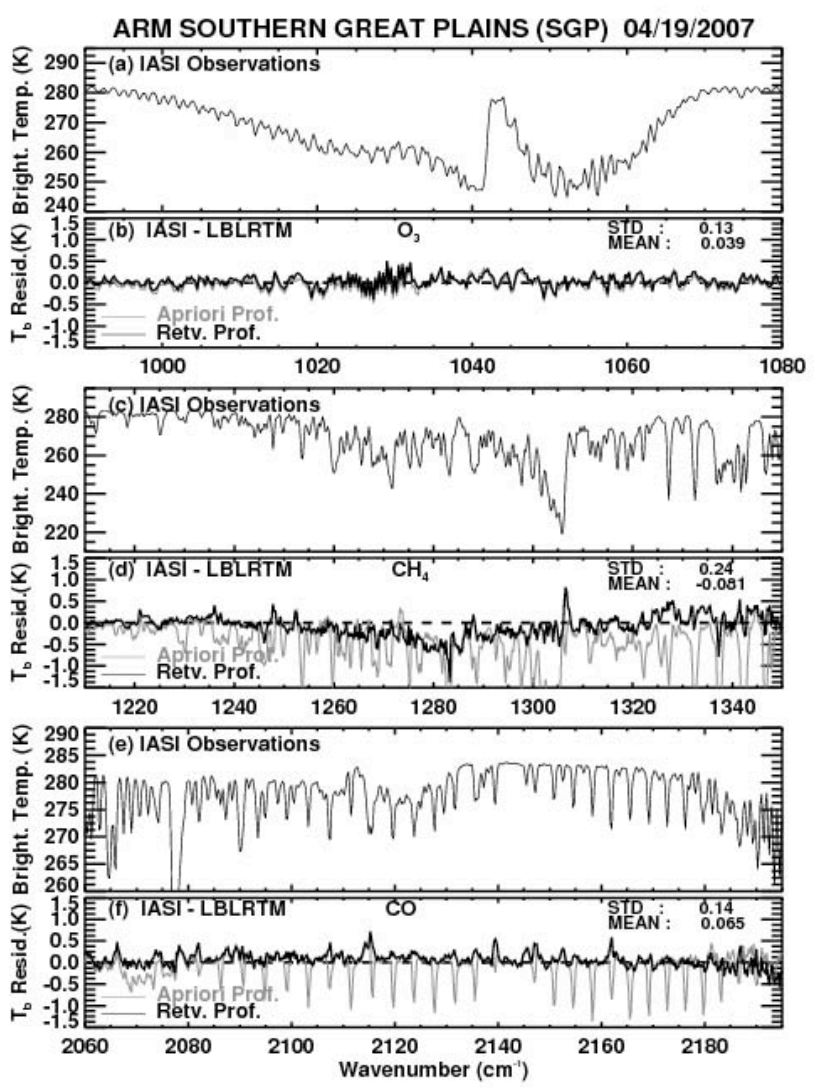

Fig. 21. IASI observations and residuals for the ARM SGP land case for the ozone region $(\mathbf{a}, \mathbf{b})$, the methane region $(\mathbf{c}, \mathbf{d})$ and the carbon monoxide region $(\mathbf{e}, \mathbf{f})$.

spread out a little bit at the IASI resolution. It has been shown in the much higher spectral resolution $\left(0.06 \mathrm{~cm}^{-1}\right)$ TES observations that the magnitude of averaged retrieved spectral residuals from the Tropospheric Emission Spectrometer (TES) in this ozone region $\left(950-1150 \mathrm{~cm}^{-1}\right)$ for clear sky cases is substantially larger than the NESR and has a distinctive shape that does not center around zero over the whole band (R. Beer, personal communication, 2008), which can indicate the presence of systematic errors. It is important to address any issues as the accuracy of the spectroscopy in the $950-1150 \mathrm{~cm}^{-1}$ ozone band has important implications for retrievals of both stratospheric and tropospheric ozone, numerical weather prediction (since a good representation of ozone is crucial for the calculation of heating rates) and chemical forecasting. One additional thing to note is that the brightness temperature residuals between IASI and LBLRTM for the a priori are good and very close to the final retrieved results indicated for this case and that the scaling of the AFGL ozone profile with the TOMS total column provided a very reasonable a priori for this case.

Methane is a very important greenhouse gas. Since methane has very little variability in the atmosphere (on the 
order of a few percent), there is a great desire to mitigate any systematic errors when retrieving methane (e.g. Payne et al., 2009). The retrieved residuals in the methane region are small with a mean around zero and a small standard deviation of $\sim 0.2 \mathrm{~K}$. Note that in Fig. $21 \mathrm{~d}$ there is a spectral signature around the $\mathrm{CH}_{4}$ Q-branch at $1305 \mathrm{~cm}^{-1}$ that is indicative of potential methane line coupling, although the effect is small. Methane line coupling coefficients are not supplied with the current release of LBLRTM, but the capability exists to produce them, thanks to the work of Tran et al. (2006).

Carbon monoxide is another important species for atmospheric chemistry. The brightness temperature residuals in Fig. 21f show that the retrieval fits the residuals very well and that there are no obvious systematic error seen in the residuals.

Figure 22 also shows that IASI is detecting minor trace gas species with weak atmospheric signatures in nadir observations. This plot shows a close-up of the $\mathrm{HNO}_{3}$ and OCS spectral residuals. In order to provide some information on the magnitude of the IASI spectral signal for these two minor species, a dotted line is provided on the two residual plots, which is the difference between IASI and an LBLRTM calculation where there are no profile amounts included. Therefore, under these conditions, the signal for both $\mathrm{HNO}_{3}$ and OCS is below $1 \mathrm{~K}$. In general, the retrieved brightness temperature residuals for both species are good with small standard deviations and means. These residual plots demonstrate the quality of both the instrument SNR and forward model needed to detect these minor species. Also note that the a priori profiles are close to the final retrieved results for both species, which suggests that the IASI scene is representative of a standard mid-latitude atmosphere for $\mathrm{HNO}_{3}$ and OCS. In order to determine the potential scientific importance of these observations, regional and global analysis are needed (e.g. Wespes et al., 2009). One important thing to keep in mind when working with any retrieved species in which there is only about 1 degree of freedom for signal (DOF) is that there is very limited vertical "profile" information. Since there is only one piece of information, the retrieval is essentially providing a weighted average mixing over the region in which the retrieval is sensitive (e.g. Payne et al., 2009; Beer et al., 2008).

\section{Summary/Conclusions}

The largest remaining uncertainties in leading-edge line-byline radiative transfer models are associated with the uncertainty in the spectroscopic parameters - line parameters, continuum and lineshape - used as input. The approach adopted for improvements to LBLRTM is to continue to implement improvements in these parameters and to continue to validate the improvements against high quality radiometric measurements. The IASI measurements have been shown to be well calibrated, both spectrally and radiometrically. The spectral

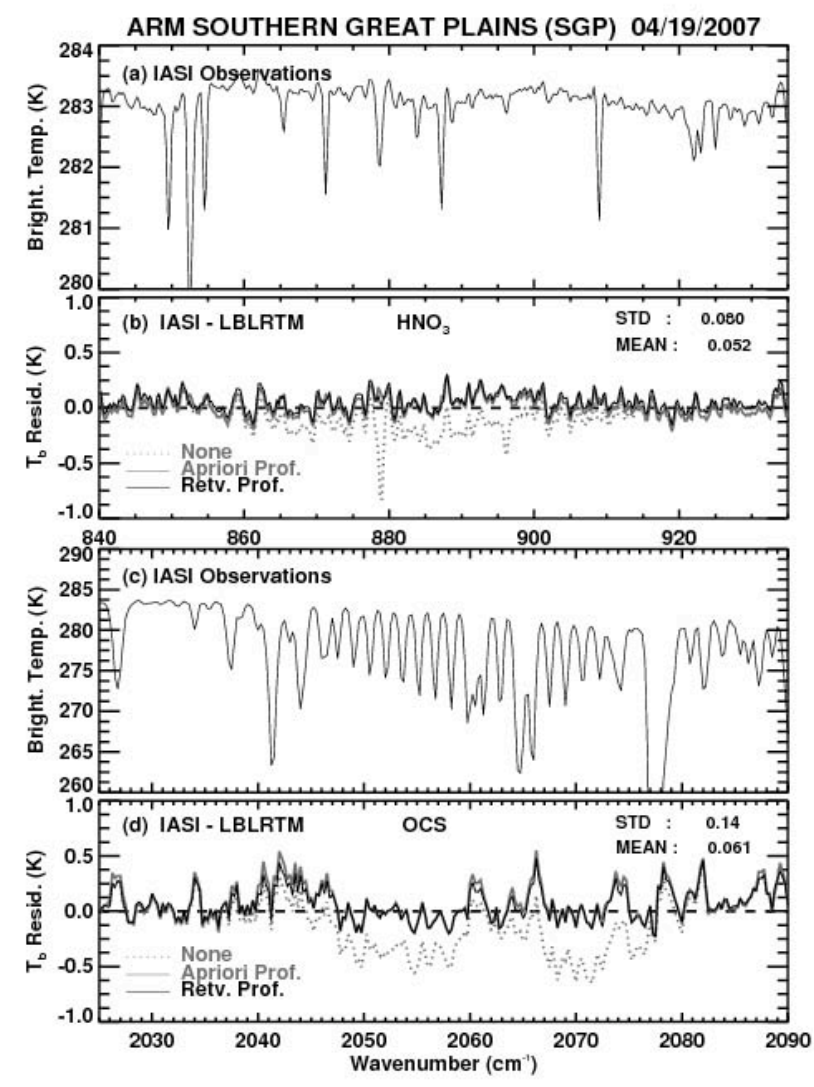

Fig. 22. Brightness temperature observations and residuals (IASILBLRTM) for the ARM SGP case for the $\mathrm{HNO}_{3}(\mathbf{a}, \mathbf{b})$ and the OCS (c, d) spectral regions.

resolution and broad, uninterrupted spectral coverage offered by IASI make this an excellent set of measurements with which to assess the current state of spectroscopic knowledge. The JAIVEx dataset, with co-located night-time radiosonde profiles over both ocean and land, has been key in this work. Detailed radiance closure studies were performed for two JAIVEx cases - one over the Gulf of Mexico and one over the ARM Southern Great Plains site in Oklahoma.

The comparisons presented here highlight a range of spectroscopy issues. For carbon dioxide, the accuracy of the lineby-line model results have benefited from the implementation of the Niro et al. (2005) line coupling coefficients (plus the corresponding updates to the $\mathrm{CO}_{2}$ continuum and chifactor). In general, the residuals in the $\mathrm{CO}_{2} v_{2}$ region are of the order of the IASI instrument noise. However, outstanding issues with the $\mathrm{CO}_{2}$ spectroscopy remain. There is a large residual $\sim-1.7 \mathrm{~K}$ in the $667 \mathrm{~cm}^{-1} \mathrm{Q}$-branch that is related to errors in the temperature profile in the upper stratosphere on into the mesopause or possible issues with the modeling of the Q-branch lines (e.g. line positions). There are clearly remaining inconsistencies between the $\mathrm{CO}_{2} v_{2}(600$ $\left.800 \mathrm{~cm}^{-1}\right)$ and $v_{3}\left(2200-2400 \mathrm{~cm}^{-1}\right)$ regions. Residuals 
Table 2. Standard deviation (or maximum error) in the retrievals in the defined spectral regions; where regions are not explicitly listed, refer to Table 1 for the spectral windows used. Values are given in brightness temperature and radiance units. The IASI noise level and the total SNR are also provided. It is important to note that the SNR computed here is for the total IASI signal in the spectral regions of interest and not just the signal of species above the background. Numbers in bold are cited in text.

\begin{tabular}{|c|c|c|c|c|}
\hline $\begin{array}{l}\text { Spectral Regions } \\
\mathrm{cm}^{-1}\end{array}$ & $\begin{array}{r}\text { Stdev } \\
\text { BT }(\mathrm{K})\end{array}$ & $\begin{array}{c}\text { Stdev } \\
\mathrm{W} / \mathrm{cm}^{2} / \mathrm{ster} / \mathrm{cm}^{-1}\end{array}$ & $\begin{array}{c}\text { Noise } \\
\mathrm{W} / \mathrm{cm}^{2} / \mathrm{ster} / \mathrm{cm}^{-1}\end{array}$ & SNR \\
\hline $\mathrm{CO}_{2} v_{2}$ Q-branch & $-1.7 *$ & $-2.05 \mathrm{E}-07 *$ & 7.18E-08 & 74.6 \\
\hline $\mathrm{CO}_{2} v_{2} \quad 700-780$ & 0.17 & 2.11E-08 & $3.78 \mathrm{E}-08$ & 220.6 \\
\hline $\mathrm{CO}_{2} \nu_{3} 2270-2375$ & 1.32 & $6.80 \mathrm{E}-10$ & $2.50 \mathrm{E}-09$ & 3.6 \\
\hline $\mathrm{CO}_{2} \nu_{3}-\mathrm{N}_{2} \mathrm{O} 2170-2260$ & 0.51 & $8.75 \mathrm{E}-10$ & 2.05E-09 & 35 \\
\hline $\mathrm{CO}_{2} v_{3} @ 2385$ & 3.08 & $1.21 \mathrm{E}-09$ & 2.67E-09 & 2.5 \\
\hline $\mathrm{CO}_{2} v_{3} 2386-2395$ & 0.52 & $8.28 \mathrm{E}-10$ & 2.67E-09 & 14.5 \\
\hline $\mathrm{H}_{2} \mathrm{O} v_{2} \mathrm{P}$-branch & 0.23 & $1.04 \mathrm{E}-08$ & $9.23 \mathrm{E}-09$ & 229.5 \\
\hline $\mathrm{H}_{2} \mathrm{O} v_{2}$ R-branch & 0.26 & $3.28 \mathrm{E}-09$ & 8.73E-09 & 41.1 \\
\hline $\mathrm{O}_{3}($ refer to Table 1$)$ & 0.14 & $1.33 \mathrm{E}-08$ & $3.29 \mathrm{E}-08$ & 152 \\
\hline $\mathrm{CH}_{4}$ (refer to Table 1$)$ & 0.24 & $1.59 \mathrm{E}-08$ & 7.23E-09 & 374.9 \\
\hline $\mathrm{CO}($ refer to Table 1$)$ & 0.13 & $8.71 \mathrm{E}-10$ & $1.92 \mathrm{E}-09$ & 92.3 \\
\hline OCS (refer to Table 1$)$ & 0.14 & $1.24 \mathrm{E}-09$ & 2.04E-09 & 122.7 \\
\hline $\mathrm{HNO}_{3}$ (refer to Table 1$)$ & 0.08 & $1.23 \mathrm{E}-08$ & $3.59 \mathrm{E}-08$ & 257.2 \\
\hline
\end{tabular}

* Is the maximum (peak) error.

in the $\mathrm{CO}_{2} \nu_{2}$ and $\nu_{3}$ spectral regions that sample the troposphere are inconsistent, with the $\mathrm{CO}_{2} \nu_{3}$ region (2170$2270 \mathrm{~cm}^{-1}$ ) being too negative (warmer) by $\sim 0.7 \mathrm{~K}$. Residuals on the lower wavenumber side of the $\mathrm{N}_{2} \mathrm{O} / \mathrm{CO}_{2} \nu_{3}$ and will be improved by line parameter updates (Perevalov and Tashkun, 2008), while future efforts to reduce the residuals on the higher wavenumber side of the $\mathrm{N}_{2} \mathrm{O} / \mathrm{CO}_{2} v_{3}$ band will focus on addressing limitations in the modeling of the $\mathrm{CO}_{2}$ line shape (line coupling and duration of collision) effects. These will also incorporate ground-based AERI measurements, which eliminate surface related issues. Refer to Table 2 for a complete summary of the errors in each spectral region.

Brightness temperature residuals from the radiance closure studies in the $\nu_{2}$ water vapor band $\left(1100-2100 \mathrm{~cm}^{-1}\right)$ have standard deviations of $\sim 0.2-0.3 \mathrm{~K}$ with some large peak residuals reaching $\pm 0.5-1.0 \mathrm{~K}$. These are larger than the instrument noise indicating that systematic errors still remain. The dominant reason for this is believed to be the variability in atmospheric water vapor over the region sampled by the IASI FOVs averaged to obtain the measurement spectra. Line intensities and positions from Coudert appear to offer some improvement over the HITRAN $2004 \mathrm{H}_{2} \mathrm{O} v_{2}$ parameters. Changing the line strengths has a significant impact on the retrieved water vapor, particularly in the upper troposphere where the differences reach $\sim 10 \%$. This is a very important result, especially in terms of assimilating infrared satellite observations (e.g. AIRS, TES, IASI) in numerical weather prediction and global circulation models. IASI residuals show evidence of water vapor line coupling, a small effect. The fact that this signature can be clearly seen in the residuals is testament to the quality of the dataset.
The MT_CKD_2.4 water vapor continuum provides good agreement with IASI measurements, apart from in the center of the water vapor $v_{2}$ band. Resolution of this issue would improve the consistency across the water vapor band. In general, evaluation of the water vapor continuum is best done from the surface, and so future efforts to improve the MT_CKD model will be focused on ground-based measurements of downwelling radiation, such as those provided by the Atmospheric Radiation Measurement (ARM) Program. Other remaining parameters to be investigated in the near future for the water vapor are the temperature dependence of the widths, pressure shifts, and line coupling.

The IASI spectra contains the information to retrieve a range of tropospheric trace gases. An in-depth assessment of the status of the spectroscopy of all these trace gases is outside the scope of this work. However, we presented some potential sources of systematic errors that will be evaluated in more detail in the near future. We also presented some examples of minor trace gases in the IASI spectral observations, which further demonstrates the quality of the IASI measurements and the LBLRTM line-by-line modeling.

Resolving outstanding issues with spectroscopy will result in advances in the accuracy of line-by-line models via improvements to consistency between information from different spectral bands for given molecules and between different molecules. This in turn will result in improvements to fast radiative transfer codes used in operational retrievals and data assimilation and in climate models, leading to improvements in weather forecasts, air quality forecasts and predictions of future climate. The high quality of the IASI dataset brings benefits not only through its direct use for retrievals and assimilation but also as a means to assess the status of 
the spectroscopy and to test alternative parameters in order to work towards resolution of the outstanding issues.

Acknowledgements. This work was partially supported by the Jet Propulsion Laboratory, California Institute of Technology, under a contract with the National Aeronautics and Space Administration and the Joint Center for Satellite Data Assimilation. IASI has been developed and built under the responsibility of the Centre National d'Etudes Spatiales (CNES, France). It is flown onboard the MetOp satellites as part of the EUMETSAT Polar System. The IASI L1 data are received through the EUMETCast near real time data distribution service. We thank to F. Niro and his group for providing line-mixing software. We would also like to thank Laurent Coudert for providing us with early access to the new water vapor line strengths and Larry Rothman and Iouli Gordon for their discussions and dedication in their continual upkeep and development of the HITRAN database as a resource for the scientific community.

Edited by: T. Wagner

\section{References}

Amato, U., Cuomo, V., and Serio, C.: Assessing the impact of radiometric noise on IASI performances, Int. J. Remote Sens., 16, 2927-2938, doi:10.1080/01431169508954599, 1995.

Amato, U., Masiello, G., Serio, C., and Viggiano, M.: The sigmaIASI code for the calculation of infrared atmospheric radiance and its derivatives, Environ. Modell. Softw., 17(7), 651-667, 2002.

Anderson, G. P., Chetwynd, J. H., Clough, S. A., Shettle, E. P., and Kneizys, F. X: AFGL: Atmospheric Constituent Profiles (0$120 \mathrm{~km}$ ), Air Force Geophysics Laboratory, Optical Physics Division, Project 7670, Hanscom Air Force Base, MA, 1986.

Beer, R., Glavich, T. A., and Rider, D. M.: Tropospheric emission spectrometer for the Earth Observing System's Aura satellite, Appl. Optics, 40 (15), 2356-2367, 2001.

Beer, R., Shephard, M. W., Kulawik, S. S., Clough, S. A., Eldering, A., Bowman, K. W., Sander, S. P., Fisher, B. M., Payne, V. H., Luo, M., Osterman, G. B., and Worden, J. R.: First satellite observations of lower tropospheric ammonia and methanol, Geophys. Res. Lett., 35, L09801, doi:10.1029/2008GL033642, 2008.

Blumstein, D., Tournier, B., Cayla, F. R., Phylpin, T., Fjortoft, R., Buil, C., and Ponce, G.: In-flight performance of the Infrared Atmospheric Sounding Interferometer (IASI) on METOP-A, SPIE, 2007.

Bowman, K. W., Rodgers, C. D., Sund-Kulawik, S., Worden, J., Sarkissian, E., Osterman, G., Steck, T., Luo, M., Eldering, A., Shephard, M. W., Worden, H., Clough, S. A., Brown, P. D., Rinsland, C. P., Lampel, M., Gunson, M., and Beer, R.: Tropospheric emission spectrometer: Retrieval method and error analysis, IEEE T. Geosci. Remote, 44(5), 1297-1307, doi:10.1109/TGRS.2006.871234, 2006.

Brown, L. R., Benner, D. C., Devo, V. M., Smith, M. A. H., and Toth, R. A.: Line mixing in self- and foreign-broadened water vapor at $6 \mu \mathrm{m}$, J. Mol. Struct., 742, 111-122, 2005.

Brown, P. D., Clough, S. A., Turner, D. D., Shippert, T. R., Knuteson, R. O., Revercomb, H. E., and Smith W. L.: The status of the quality measurement experiments in the microwave, longwave, and shortwave, in: Proceedings of the Seventh Atmospheric Radiation Measurement (ARM) Science Team Meeting, US Department of Energy, CONF-970365, 499-504, available URL: http://www.arm.gov/publications/proceedings/ conf07/abstracts/brown-97.pdf, 1998.

Cady-Pereira, K. E., Shephard, M. W., Turner, D. D., Mlawer, E. J., and Clough, S. A.: Improved Total Column Precipitable Water Vapor from Vaisala RS90 and RS92 Humidity Sensors, J. Atmos. Ocean. Tech., 25, 6, doi:10.1175/2007JTECHA1027.1, 2008.

Chalon, G., Cayla, F., and Diebel, D.: IASI: An advanced sounder for operational meteorology, Proceedings of the 52nd Congress of the International Astronautical Federation, Toulouse, France, 1-5 October 2001.

Clerbaux, C., Hadji-Lazaro, J., Turquety, S., George, M., Coheur, P.-F., Hurtmans, D., Wespes, C., Herbin, H., Blumstein, D., Tournier, B., and Phulpin, T.: The IASI/MetOp I Mission: First observations and highlights of its potential contribution to GMES, COSPAR Inf. Bul., 2007, 20, 19-24, 2007.

Clerbaux, C., Boynard, A., Clarisse, L., George, M., Hadji-Lazaro, J., Herbin, H., Hurtmans, D., Pommier, M., Razavi, A., Turquety, S., Wespes, C., and Coheur, P.-F.: Monitoring of atmospheric composition using the thermal infrared IASI/MetOp sounder, Atmos. Chem. Phys., 9, 6041-6054, 2009, http://www.atmos-chem-phys.net/9/6041/2009/.

Clough, S. A., Iacono, M. J., and Moncet, J.-L.: Line by line calculation of atmospheric fluxes and cooling rates: application to water vapor, J. Geophys. Res., 97, 15761-15785, 1992.

Clough, S. A., Rinsland, C. P., and Brown, P. D.: Retrieval of tropospheric ozone from simulations of nadir spectral radiances as observed from space, J. Geophys. Res., 100(D8), 16579-16593, 1995.

Clough, S. A., Shephard, M. W., Mlawer, E. J., Delamere, J. S., Iacono, M. J., Cady-Pereira, K., Boukabara, S., and Brown, R. D.: Atmospheric radiative transfer modeling: a summary of the AER codes, J. Quant. Spectrosc. Ra., 91, 233-244, 2005.

Clough, S. A., Shephard, M. W., Worden, J., Brown, P. D., Worden, H. M., Luo, M., Rodgers, C. D., Rinsland, C. P., Goldman, A., Brown, L., Kulawik, S. S., Eldering, A., Lampel, M. C., Osterman, G., Beer, R., Bowman, K., Cady-Pereira, K. E., and Mlawer, E. J.: Forward Model and Jacobians for Tropospheric Emission Spectrometer Retrievals, IEEE T. Geosci. Remote, 44, 1308-1323, 2006.

Coudert, L. H., Wagner, G., Birk, M., Baranov, Yu, I., Lafferty, W. J., and Flaud, J.-M.: The $\mathrm{H}_{2} 16 \mathrm{O}$ molecule: Line position and line intensity analyses up to the second triad, J. Mol. Spectrosc., 251(1-2), doi:10.1016/j.jms.2008.03.021, 2008.

Fischer, J., Gamache, R. R., Goldman, A., Rothman, L. S., and Perrin, A.: Total internal partition sums for molecular species in the 2000 edition of the HITRAN database, J. Quant. Spectrosc. Ra., 82, 401-412, 2003.

Flaud, J.-M., Piccolo, C., Carli, B., Perrin, A., Coudert, L. H., Teffo, J.-L., and Brown, L. R.: Molecular line parameters for the MIPAS (Michelson Interferometer for Passive Atmospheric Sounding) experiment, J. Atmos. Ocean Opt., 16, 172-182, 2003.

Gordon, I. E., Rothman, L. S., Gamache, R. R., Jaquemart, D., Boone, C., Bernath, P. F., Shephard, M. W., Delamere, J. S., and Clough, S. A.: Current updates of the water-vapor line list in HITRAN: A new "Diet" for air-broadened half-widths, 108, 
doi:10.1016/j.jqsrt.2007.06.009, 2007.

Iacono, M. J., Delamere, J. S., Mlawer, E. J., Shephard, M. W., Clough, S. A., and Collins, W. D.: Radiative forcing by long-lived greenhouse gases: Calculations with the AER radiative transfer models, J. Geophys. Res., 113, D13103, doi:10.1029/2008JD009944, 2008.

Joiner, J., Brin, E., Treadon, R., Derber, J., Van Delst, P., Da Silva, J. A., Le Marshall, P., Poli, P., Atlas, R., Bungato, D., and Cruz, C.: Effects of data selection and error specification on the assimilation of AIRS data, Q. J. Roy. Meteorol. Soc., 133, 181-196, 2007.

Masiello, G., Serio, C., Carissimo, A., Grieco, G., and Matricardi, M.: Application of $\Phi$-IASI to IASI: retrieval products evaluation and radiative transfer consistency, Atmos. Chem. Phys. Discuss., 9, 9647-9691, 2009,

http://www.atmos-chem-phys-discuss.net/9/9647/2009/.

Matricardi, M.: An assessment of the accuracy of the RTTOV fast radiative transfer model using IASI data, Atmos. Chem. Phys. Discuss., 9, 9491-9535, 2009,

http://www.atmos-chem-phys-discuss.net/9/9491/2009/.

McMillin, L. M. and Fleming, H. E.: Atmospheric transmittance of an absorbing gas 3: a computationally fast and accurate transmittance model for absorbing gases with variable mixing ratios, Appl. Optics, 18, 1600-1606, 1979.

Miloshevich, L. M., Voemel, H., Whiteman, D. N., Lesht, B. M., Schmidlin, F. J., and Russo, F.: Absolute accuracy of water vapor measurements from six operational radiosonde types launched during AWEX-G and implications for AIRS validation, J. Geophys. Res., 111, D09S10, doi:10.1029/2005JD006083, 2006.

Mlawer, E. J., Taubman, S. J., Brown, P. D., Iacono, M. J., and Clough, S. A.: Radiative transfer for inhomogeneous atmospheres: RRTM, a validated correlated-k model for the longwave, J. Geophys. Res., 102D, 16663-16682, 1997.

Moncet, J., Uymin, G., Lipton, A. E., and Snell, H. E.: Infrared radiance modeling by optimal spectral sampling, J. Atmos. Sci., 65, 3917-3934, 2008.

Niro, F., Jucks, K., and Hartmann, J.-M.: Spectral calculations in central and wing regions of $\mathrm{CO}_{2}$ IR bands, IV: Software and database for the computation of atmospheric spectra, J. Quant. Spectrosc. Ra., 95, 469-481, 2005.

Payne, V. H., Clough, S. A., Shephard, M. W., Nassar, R., and Logan, J. A.: Information-centered representation of retrievals with limited degrees of freedom for signal: Application to methane from the Tropospheric Emission Spectrometer, submitted to J. Geophys. Res., 2009.

Perevalov, V. I. and Tashkun, S. A.: CDSD-296 (Carbon Dioxide Spectroscopic Databank): Updated and Enlarged Version for Atmospheric Applications, Proceedings of the 10th HITRAN database conference, Cambridge, MA, USA, June 2008.

Phulpin, T., Blumstein, D., Prel, F., Tournier, B., Prunet, P., and Schlussel, P.: Applications of IASI on MetOp-A: first results and illustration of potential use for meteorology, climate monitoring, and atmospheric chemistry, 6684, 66840F.1-66840F.12, doi:10.1117/12.736816, 2007.

Remedios, J. J., Leigh, R. J., Waterfall, A. M., Moore, D. P., Sembhi, H., Parkes, I., Greenhough, J., Chipperfield, M.P., and Hauglustaine, D.: MIPAS reference atmospheres and comparisons to V4.61/V4.62 MIPAS level 2 geophysical data sets, Atmos. Chem. Phys. Discuss., 7, 9973-10017, 2007, http://www.atmos-chem-phys-discuss.net/7/9973/2007/.

Revercomb, H. E., Buijs, H., Howell, H. B., Laporte, D. D., Smith, W. L., and Sromovsky, L. A.: Radiometric calibration of IR Fourier-transform spectrometers - solution to a problem with the high resolution interferometer sounder, Appl. Optics, 27, 3210 3218, 1988.

Revercomb, H. E., Knuteson, R. O., Best, F. A., Tobin, D. C., Smith, W. L., LaPorte, D. D., Ellington, S. D., Werner, M. W., Dedecker, R. G., Garcia, R. K., Ciganovich, N. N., and Howell, H. B.: Scanning High-resolution Interferometer Sounder (S-HIS) aircraft instrument and validation of the Atmospheric InfraRed Sounder (AIRS), in: Optical Remote Sensing, OSA Technical Digest (Optical Society of America, 2003), paper JMA4, 2003.

Rodgers, C. D.: Inverse Methods for Atmospheric Sounding: Theory and Practice, World Sci., Hackensack, N. J., 2000.

Rothman, L. S., Rinsland, C. P., Goldman, A., Massie, S. T., Edwards, D. P., Flaud, J.-M., Perrin, A., Camy-Peyret, C., Dana, V., Mandin, J.-Y., Schroeder, J., McCann, A., Gamache, A. A., Wattson, R. B., Yoshino, K., Chance, K. V., Jucks, K. W., Brown, L. R., Nemtchinov, V., and Varanasi, P.: The HITRAN molecular spectroscopic database and HAWKS (HITRAN Atmospheric Work Station), J. Quant. Spectrosc. Ra., 1996 edition, 60, 665710, 1998.

Rothman, L. S., Jaquemart, D., Barbe, A., Benner, C. D., Birk, M., Brown, L. R., Carleer, M. R., Chackerian, C., Chance, K., Coudert, L. H., Dana, V., Devi, V. M., Flaud, J.-M., Gamache, R. R., Goldman, A., Hartmann, J.-M., Jucks, K. W., Maki, A. G., Mandin, J.-Y., Massie, S. T., Orphal, J., Perrin, A., Rinsland, C. P., Smith, M. A. H., Tennyson, J., Tolchenov, R. N., Toth, R. A., Vander Auwera, J., Varanasi, P., and Wagner, G.: The HITRAN 2004 molecular spectroscopic database, J. Quant. Spectrosc. Ra., 96, 139-204, 2005.

Shephard, M. W., Herman, R. L., Fisher, B. M., Cady-Pereira, K. E., Clough, S. A., Payne, V. H., Whiteman, D. N., Comer, J. P., Volmer, H., Miloshevich, L. M., Forno, R., Adam, M., Osterman, G. B., Eldering, A., Worden, J. R., Brown, L. R., Worden, H. M., Kulawik, S. S., Rider, D. M., Goldman, A., Beer, R., Bowman, K. W., Rodgers, C. D., Luo, M., Rinsland, C. P., Lampel, M., and Gunson, M. R.: Comparison of Tropospheric Emission Spectrometer nadir water vapor retrievals with in situ measurements, J. Geophys. Res., 113(D15), D15S24, doi:10.1029/2007JD008822, 2008a.

Shephard, M. W., Payne, V. H., Cady-Pereira, K. E., Herman, R. L., Kulawik, S. S., Fisher, B. M., Eldering, A., and Clough, S. A.: "Investigation of biases in the TES temperature retrievals", AGU Joint Assembly, Fort Lauderdale, FL, USA, 27-30 May, 2008b.

Smith, W. L., Feltz, W. F., Knuteson, R. O., Revercomb, H. E., Woolf, H. M., and Howell, H. B.: The retrieval of planetary boundary layer structure using ground-based infrared spectral radiance measurements, J. Atmos. Ocean. Tech., 16, 323-333, 1999.

Smith, W. L., Revercomb, H. E., Zhou, D. K., and Huang, H. L.: Hyperspectral sounding - a revolutionary advance in atmospheric remote sensing Conference Information: Conference on Multispectral and Hyperspectral Remote Sensing Instruments and Applications II, Date: 09-11 November 2004 Honolulu HI, Source: MULTISPECTRAL AND HYPERSPECTRAL REMOTE SENSING INSTRUMENTS AND APPLICATIONS II, 5655, 1-11, ISSN 0277-786X, 2005. 
Smith, W. L., Larar, A., Taylor, J., Revercomb, H., Kireev, S., Zhou, D., Liu, X., Tobin, D., Newman, S., Schluessel, P., Clough, S. A., Mango, S., and St. Germain, K.: Joint Airborne IASI Validation Experiment (JAIVEx) - An overview, Proceedings of the ITSCXVI Angra dos Reis, Brazil, 7-13 May 2008.

Strow, L. L., Hannon, S. E., De Souza Machado, S., Motteler, H. E., and Tobin, D.: An overview of the AIRS radiative transfer model, IEEE T. Geosci. Remote, 41, 303-313, 2003.

Strow, L. L., Hannon, S. E., De-Souza Machado, S., Motteler, H. E., and Tobin, D. C.: Validation of the Atmospheric Infrared Sounder radiative transfer algorithm, J. Geophys. Res., 111, D09S06, doi:10.1029/2005JD006146, 2006.

Tashkun, S. A., Perevalov, V. I., Teffo, J. L., Rothman, L. S., and Tyuterev, V. G.: "Global fitting of $\mathrm{CO}_{2}$ vibration-rotation line positions using the effective Hamiltonian approach", J. Quant. Spectrosc. Ra., 60, 785-801, 1998.

Tashkun, S. A., Perevalov, V. I., Teffo, J. L., and Tyuterev, V. G.: Global fitting of $12 \mathrm{C} 16 \mathrm{O}_{2}$ vibration-rotation line intensities using the effective operator approach, J. Quant. Spectrosc. Ra., 62, 571-598, 1999a.

Tashkun, S. A., Perevalov, V. I., and Teffo, J. L.: CDSD: a high precision high temperature spectroscopic databank of the $\mathrm{CO}_{2}$ molecule, Ve Colloque Atmospheric Spectroscopy Applications, Reims, 1-3 September, 1999b.

Tjemkes, S. A., Patterson, T., Rizzi, R., Shephard, M. W., Clough, S. A., Matricardi, M., Haigh, J. D., Hopfner, M., Payan, S., Trotsenko, A., Scott, N., Rayer, P., Taylor, J. P., Clerbaux, C., Strow, L. L., DeSouza-Machado, S., Tobin, D., and Knuteson, R.: The ISSWG line-by-line inter-comparison experiment, J. Quant. Spectrosc. Ra., 77, 433-453, 2003.

Tobin, D. C., Revercomb, H. E., Knuteson, R. O., Lesht, B. M., Strow, L. L., Hannon, S. E., Feltz, W. F., Moy, L. A., Fetzer, E. J., and Cress, T. S.: Atmospheric Radiation Measurement site atmospheric state best estimates for Atmospheric Infrared Sounder temperature and water vapor retrieval validation, J. Geophys. Res., 111, D09S14, doi:10.1029/2005JD006103, 2006.

Tran, H., Flaud, P.-M., Gabard, T., Hase, F., von Clarmann, T., Camy-Peyret, C., Payan, S., and Hartmann, J.-M.: Model, software and database for line-mixing effects in the $\mathrm{v}_{3}$ and $\mathrm{v}_{4}$ bands of $\mathrm{CH}_{4}$ and tests using laboratory and planetary measurements - I: $\mathrm{N}_{2}$ (and air) broadenings and the earth atmosphere, J. Spectrosc. Ra., 101, 284-305, 2006.
Turner, D. D., Lesht, B. M., Clough, S. A., Liljegren, J. C., Revercomb, H. E., and Tobin, D. C.: Dry Bias and Variability in Vaisala RS80-H Radiosondes: The ARM Experience, J. Atmos. Ocean. Tech., 20, 117-132, 2003.

Turner, D. D., Tobin, D. C., Clough, S. A., Brown, P. D., Ellingson, R. G., Mlawer, E. J., Knuteson, R. O., Revercomb, H. E., Shippert, T. R., and Smith, W. L.: The QME AERI LBLRTM: A closure experiment for downwelling high spectral resolution infrared radiance, J. Atmos. Sci, 61, 2657-2675, 2004.

van Delst, P. F. W. and Wu, X.: A high resolution infrared sea surface emissivity database for satellite applications, Technical Proceedings of The Eleventh International ATOVS Study Conference, Budapest, Hungary, 20-26 September 2000, 407-411, 2000.

Vömel, H., Selkirk, H., Miloshevich, L., Valverde, J., Valdés, J., Kyrö, E., Kivi, R., Stolz, W., Peng, G., and Diaz, J. A.: Radiation dry bias of the Vaisala RS92 humidity sensor, J. Atmos. Ocean. Tech., 24, 953-963, 2006.

Wattson, W. B. and Rothman, L. S.: Direct numerical diagonalization - Wave of the future, J. Quant. Spectrosc. Ra., 48, 763-780, 1992.

Wespes, C., Hurtmans, D., Clerbaux, C., Santee, M. L., Martin, R. V., and Coheur, P. F.: Global distributions of nitric acid from IASI/MetOP measurements, Atmos. Chem. Phys. Discuss., 9, 8035-8069, 2009,

http://www.atmos-chem-phys-discuss.net/9/8035/2009/.

$\mathrm{Wu}, \mathrm{X}$. and Smith, W. L.: Emissivity of rough sea surface for 8 $13 \mu \mathrm{m}$ : modeling and verification, Appl. Optics, 36, 2609-2619, 1997.

Zhou, D. K., Smith, W. L., Cuomo, V., Taylor, J. P., Barnet, C. D., Di Girolamo, P., Pappalardo, G., Larar, A. M., Liu, X., Newman, S. M., Lee, C., and Mango, S. A.: Retrieval validation during the European Aqua Thermodynamic Experiment, Q. J. Roy. Meteorol. Soc. 133, 203-215, 2007. 